\title{
Welfare costs of reclassification risk in the health
}

\author{
insurance market
}

\author{
Svetlana Pashchenko* \\ University of Surrey
}

\author{
Ponpoje Porapakkarm ${ }^{\dagger}$ \\ National Graduate Institute \\ for Policy Studies (GRIPS)
}

April 7, 2015

\begin{abstract}
We assess the quantitative importance of reclassification risk in the US health insurance market. Reclassification risk arises because the health conditions of individuals evolve over time, while a typical health insurance contract only lasts for one year. Thus, a change in the health status can lead to a significant change in the health insurance premium. We measure welfare gains from introducing explicit insurance against this risk in the form of guaranteed renewable health insurance contracts. We find that in the current institutional environment individuals are well-sheltered against reclassification risk and they only moderately gain from having access to these contracts. More specifically, we show that employer-sponsored health insurance and public means-tested transfers play an important role in providing implicit insurance against reclassification risk. If these institutions are removed, the average welfare gains from having access to guaranteed renewable contracts exceed $4 \%$ of the annual consumption.
\end{abstract}

Keywords: health insurance, reclassification risk, dynamic insurance, guaranteed renewable contracts, general equilibrium JEL Classification Codes: D52, D58, D91, G22, I11

\footnotetext{
${ }^{*}$ Corresponding author. Address: School of Economics, Faculty of Business, Economics and Law, University of Surrey, Guildford, GU2 7XH, UK, Tel. +44 148368 2773. Email: svetlanap.econ@gmail.com

${ }^{\dagger}$ Email: p-porapakkarm@grips.ac.jp
} 


\section{Introduction}

An important feature of the health insurance market is that a typical insurance policy only lasts for one year while a disease can last for any period of time. This creates the problem of reclassification risk - a risk to face a drastic increase in health premiums when one's health condition deteriorates. The fact that standard health insurance contracts leave individuals exposed to reclassification risk is considered an important market failure in the health insurance market (Hendel and Lizzeri, 2003; Diamond, 1992). Moreover, the observation that sick people face high health insurance premiums was an important argument for an additional regulation on health insurance market during the 2009-2010 health reform debate. ${ }^{1}$ The aim of this paper is to evaluate how important is the lack of protection against reclassification risk for the welfare of consumers.

One way to do this is to compare the current system with the first best solution to the problem of reclassification risk which is to enroll everyone into a long-term health insurance contract. The price of such contract depends on the average expected medical expenses of all participants. In other words, healthy people make transfers to the sick equalizing the insurance price for all risk categories. This contract requires consumers' commitment because healthy individuals tend to drop out. As shown by Cochrane (1995), the lack of commitment can be overcome by introducing a special arrangement such as illiquid accounts ${ }^{2}$. Another problem with ensuring participation in this contract is the incomplete labor markets. Since premiums are based on the average medical expenses but not on individual income, consumers experiencing a sequence of bad income shocks may be unable to pay the premium. This can be solved by introducing income-based transfers. However, since all income redistributive measures have a non-trivial effect on welfare, it is hard to measure pure welfare effects of reclassification risk in the presence

\footnotetext{
${ }^{1}$ This debate resulted in the major health reform bill that was signed in 2010. Among other things, this bill forbids insurance companies to risk-adjust premiums in the individual market. This can be considered as a regulatory way to remove reclassification risk. We discuss implications of our results for the health reform in Section 6.

${ }^{2}$ More specifically, Cochrane's idea is to substitute a long-term contract with a sequence of shortterm contracts that require consumers who turn out to be healthy to make transfers to insurance firms. Illiquid accounts are needed to enforce these transfers.
} 
of these transfers.

To overcome this problem, we consider a special type of contracts that can provide insurance against reclassification risk without requiring consumers' commitment, incomebased transfers or any other special arrangements. These are guaranteed renewable contracts discussed in detail by Pauly et al. (1995). These contracts are front-loaded: a consumer is required to prepay part of his future premiums and this prepayment locks him into the contract. ${ }^{3}$ In return, a consumer is guaranteed that i) he will be able to renew his health insurance contract in the future; ii) the prespecified renewal price will be independent of his future health realization. A key feature of this type of contracts is that reclassification risk is insured not by making healthy people pay for the sick but by allowing individuals to make state-contingent savings that pay off when their premiums increase. ${ }^{4}$ To evaluate the welfare costs of reclassification risk, we consider how much welfare improvement can be achieved from introducing guaranteed renewable contracts into the individual health insurance market. ${ }^{5}$

We construct a general equilibrium overlapping generations model where people face uninsurable labor income risk and medical expense risk that can be partially insured. Several types of health insurance are available. First, some individuals have access to employer-based insurance. Second, low-income individuals can get Medicaid. Finally, all individuals can buy insurance policy directly in the individual market where premiums are risk-rated, i.e. depend on the current health conditions of individuals. All policies last for one year while medical shocks are persistent, which creates the problem of reclassification

\footnotetext{
${ }^{3}$ Hendel and Lizzeri (2003) show that front-loaded contracts are optimal in the absence of consumers' commitment.

${ }^{4}$ It is important to point out the fundamental difference between these guaranteed renewable contracts and the regulatory guaranteed renewability provision that exists in some states of the US. The guaranteed renewability provision forbids insurance companies from denying coverage to individuals who already have an insurance contract and want to renew it. However, this provision does not require that the price at renewal is fixed at some prespecified level. In contrast, the key feature of guaranteed renewable contracts is that they allow to predetermine renewal price in advance.

${ }^{5}$ More specifically, in order to measure welfare costs of reclassification risk we introduce a frictionless market offering guaranteed renewable contracts. An alternative modeling strategy is to allow this market to exist in the baseline economy but with frictions that prevent people from using it. Then we can quantify how large are these frictions. Our results are robust to this alternative modeling strategy. In the Appendix we show that relatively small fixed costs are sufficient to deter people from buying guaranteed renewable contracts, which possibly explains why we do not observe these contracts offered in reality.
} 
risk.

Our model reflects two institutional features that are essential when evaluating the importance of reclassification risk in the U.S. health insurance market. First, a large proportion of non-elderly adults buys their insurance from the employer-based market. This market is community rated, i.e. premiums are independent of the health conditions of individuals. People with permanent access to this market are protected from the risk of premium fluctuations. Also, low-income individuals can get public insurance from Medicaid for free. Second, for people facing high medical shocks and/or bad labor income shocks, the government provides protection in the form of the consumption minimum floor which can also mitigate the consequences of the lack of explicit insurance against reclassification risk.

We calibrate the model using the Medical Expenditure Panel Survey dataset to match the key insurance statistics for the U.S. Using the calibrated model we study the quantitative implications of introducing frictionless guaranteed renewable contracts into the individual market.

We find that comparing to the situation when only standard short-term insurance contracts are available, the introduction of guaranteed renewable contracts can noticeably decrease uninsurance rates - from $25.9 \%$ to $19.4 \%$ due to higher participation in the individual insurance market. Also, when both standard and guaranteed renewable contracts are available, most of the consumers prefer to buy the latter type. Our results show that people who hold guaranteed renewable contracts face almost no fluctuations in their health insurance premiums even if their health deteriorates. This implies that these contracts provide good protection against reclassification risk.

In terms of welfare, we find that the introduction of guaranteed renewable contracts brings small average welfare gains $(0.07 \%$ of the annual consumption) because in the current U.S. institutional environment people are well-sheltered against reclassification risk. More specifically, we show that several institutions provide good implicit insurance against reclassification risk. First, employer-sponsored health insurance, which protects mostly high-income people; and second, the consumption minimum floor, which protects 
mostly people with low income. If these institutions are removed, the average welfare gains from having access to guaranteed renewable contracts exceed $4 \%$ of the annual consumption.

This paper belongs to two strands of literature. First is the literature studying how private markets can provide insurance against reclassification risk if buyers cannot commit to a contract. A seminal paper in this area is Cochrane (1995) who characterizes a set of contracts that can provide long-term health insurance in such an environment. His insight is to combine standard one-period insurance contracts with premium insurance, i.e. insurance against future premium fluctuations. One requirement for such premium insurance to work is that each consumer needs to open a special account that works as a clearing house between him and the insurance company. An important condition is that consumers cannot freely withdraw money from this account. One special case in this set of contracts that can work without a special account are front-loaded guaranteed renewable contracts proposed by Pauly et al. (1995). Front-loaded contracts were also studied by Hendel and Lizzeri (2003) for the life insurance market. They showed that the structure of premiums in this market is consistent with front-loaded contracts that emerge in the absence of consumers' commitment. Finkelstein et al. (2005) studied front-loaded contracts in the long-term care insurance market and showed that the current amount of front-loading is not sufficient to lock consumers into the contracts. To the best of our knowledge, our paper is the first one that studies guaranteed renewable contracts in the health insurance market using a general equilibrium framework and taking into account existing institutions in the US.

The second strand of literature this paper belongs to studies quantitative heterogeneous agent models with incomplete markets augmented by (i) medical expense shocks and (ii) health insurance markets where individuals can partially insure these shocks. This branch of incomplete market literature has emerged recently and includes, among others, papers by Kitao and Jeske (2009) who study subsidies for employer-based insurance, Hansen et al. (2014) who evaluate the consequences of expanding Medicare program, Hsu (2013) who studies the effect of private health insurance on savings, and 
Pashchenko and Porapakkarm (2013) who study the current health reform in the U.S. These studies consider an environment when only one type of contract is available in the individual health insurance market. Our contribution to this literature is that we expand the contract space by allowing insurance firms to offer guaranteed renewable contracts. Since it is a long-term contract, this extension involves solving a dynamic contracting problem within a general equilibrium framework.

\section{Simple illustration}

This section constructs a simple example to illustrate how a guaranteed renewable contract works. Consider an individual whose health is good, and the price he pays for a standard one-period health insurance contract is $p_{L}$. With probability $v$ an individual may still be in good health in the next period, in which case his health insurance premium will stay unchanged. However, with probability $1-v$ his health status may deteriorate. If this happens, his health insurance premium for the standard contract will rise to $p_{H}$, where $p_{H}>p_{L}$. If an individual buys the standard one-period contract, he is exposed to reclassification risk - the risk that his health premium will rise from $p_{L}$ to $p_{H}$.

Suppose an individual has the option to buy a guaranteed renewable contract at the price $p_{1}^{G R}$. This contract insures his medical expenditure in the next period like the standard one-period contract. In addition, it guarantees that in the next period he can

buy health insurance at the prespecified price $p_{2}^{G R}$ that does not depend on his health status realization. If his health status remains the same, he can buy a standard contract at price $p_{L}$. However, if his health status deteriorates he can renew his guaranteed renewable contract at price $p_{2}^{G R}<p_{H}$. Assuming perfect competition in the insurance market, the price of such a guaranteed renewable contract is determined in the following way:

$$
p_{1}^{G R}=p_{L}+(1-v)\left(p_{H}-p_{2}^{G R}\right)
$$

Note that the guaranteed renewable contract is more expensive than the regular one- 
period contract because of the front-loading part $(1-v)\left(p_{H}-p_{2}^{G R}\right)$. This front-loading takes into account the fact that an individual can become unhealthy but the price of renewing his health insurance $\left(p_{2}^{G R}\right)$ cannot be readjusted.

\section{Model}

\subsection{Households}

The economy is populated by two overlapping generations: young and old. A young individual stays young with probability $\zeta^{y}$ and becomes old with probability $1-\zeta^{y}$. An old individual survives to the next period with probability $\zeta^{o}{ }^{6}$ The population is assumed to remain constant. Old agents who die are replaced by the entry of new young agents.

An individual discounts his future utility by the discount factor $\beta$. Preferences are described by the CRRA utility function with the risk aversion parameter $\sigma$ :

$$
u(c)=\frac{c^{1-\sigma}}{1-\sigma} .
$$

\section{Health insurance}

An individual's health status $h$ is indexed by $\{1,2, . ., H\}$. An increasing number implies deteriorating health status. Health status evolves according to an $H$-state Markov process, where $G^{y}\left(h^{\prime} \mid h\right)$ stands for the young and $G^{o}\left(h^{\prime} \mid h\right)$ for the old. The current health status of an individual determines his current medical expenditure $x(h)$, where $x$ is a deterministic and strictly monotone-increasing function, different between the young and the old. Thus, we will refer to health status $(h)$ and medical expenditure $(x)$ interchange-

\footnotetext{
${ }^{6}$ We assume a stochastic aging environment because a full life-cycle model is computationally impractical in our framework. The most time-consuming part of our computations is to find equilibrium prices of guaranteed renewable contracts. In a stochastic aging model this price depends only on health status. In the full life-cycle model, the price will be a function of both age and health, making our model computationally infeasible, especially regarding transition calculations. In Section 4.3 we explain how we adjust our calibration strategy to approximate for the key life-cycle features. In Section 7 we discuss how our results can be affected by this assumption.
} 
ably.

Each young individual can buy insurance against the next period medical expenditures in the individual insurance market where two types of contracts are offered. The first is a standard one-year contract that covers some fraction of the next period medical expenditure. The price of this contract depends on the current health status of an individual and is denoted by $p^{I}(h)$. The second type of contracts is guaranteed renewable. This contract covers a fraction of the next period's medical expenditure, like a standard one-year contract, but also provides an option to renew the insurance in the following period at the same price, regardless of the new health status ${ }^{7}$. Guaranteed renewable contracts do not have a termination date, i.e. an individual can renew the same contract as long as he is still young, with an important condition of continuous participation. In other words, if an individual does not renew the contract once, he will lose the option to renew it in the future. The premium of a newly issued guaranteed renewable contract is a function of the current health status of an individual. The price of a guaranteed renewable contract that is already in force is fixed and determined by the health status of an individual at the time of the contract initiation.

In each period, with some probability, a young individual can get an offer to buy employer-sponsored health insurance (ESHI). This is denoted by $g: g=1$ if an individual gets an ESHI offer, $g=0$ if he does not. ${ }^{8}$ The out-of-pocket premium of employer-based insurance is equal to

$$
\bar{p}=(1-\psi) p
$$

Here $p$ is the premium charged to all participants of the employer-based pool, and $\psi$ is

\footnotetext{
${ }^{7}$ There are several ways to design a guaranteed renewable contract, by changing the price that an insurer guarantees at the renewal. In our main experiments we assume that the renewal price is the same as the price of the original contract. Later, we relax this assumption by allowing the renewal price to differ from the original price. Detailed discussion of these experiments is provided in Section 8.

${ }^{8}$ We incorporate an important feature of the data that many individuals do not have permanent access to ESHI, but can lose this access several times during their working life. We do not explicitly model COBRA which provides the possibility for some individuals to extend their access to the employer-based pool for a limited time period after they lose their ESHI offer. Modeling COBRA requires us to add an additional state variable, making our computation of the transition impractical. In addition, COBRA is not effective in eliminating the problem of fragmented access to ESHI and thus will not conceptually change our model.
} 
the fraction of this premium paid by the employer.

Low-income individuals are eligible to enroll in Medicaid, which provides health insurance for free. To become eligible for Medicaid, an individual's total resources net of out-of-pocket medical expenses must be below a certain level denoted by $y^{p u b}$.

We use $i$ to index the current health insurance status as follows:

$$
i=\left\{\begin{array}{ll}
-2 & ; \text { if uninsured } \\
-1 & ; \text { if insured by Medicaid } \\
0 & ; \text { if holding a standard one-period insurance or ESHI } \\
1,2, \ldots, H & ; \text { if holding a guaranteed renewable contract originated when } \\
& \text { his health status equals } i .
\end{array}\right\}
$$

If an individual holds a guaranteed renewable contract, $i$ keeps track of the health status when the contract was initiated. For a newly purchased contract $i$ is the current health status $h$. We denote the premium for a newly issued guaranteed renewable insurance as $p^{G R}(h)$, and the premium for a guaranteed renewable contract that is already in force as $p^{G R}(i)$ for $i=\{1,2, \ldots, H\}$.

If a young person is insured, the insurance will cover a fraction $q(i, x)$ of his current medical expenses. This fraction depends on his medical expenditure $(x)$ and the type of insurance he has $(i)$.

All retired households are enrolled in Medicare. Medicare charges a premium of $p^{\text {med }}$. We denote the fraction of medical expenses covered by Medicare by $q^{\text {med }}(x)$.

\section{Labor income, taxation and social transfers}

A young individual supplies labor inelastically. ${ }^{9}$ We denote his earnings by $\widetilde{w} z$, where $\widetilde{w}$ is the adjusted wage per effective labor unit and $z$ is his idiosyncratic productivity. We model the productivity, an ESHI offer, and health status as a joint Markov process. The productivity of the old is set to zero.

\footnotetext{
${ }^{9}$ In our environment, the value of guaranteed renewable contracts is in decreasing consumption fluctuations arising from reclassification risk. If we assume that labor supply is elastic, guaranteed renewable contracts may have an additional value of mitigating job lock. Job lock arises if an individual cannot stop working because he is afraid of losing his health insurance. The availability of guaranteed renewable contracts may resolve the job lock problem, as individuals can obtain relatively cheap health insurance outside the employer-based market. Thus, our estimated welfare gains from guaranteed renewable contracts can be considered a low bound.
} 
Each household has to pay income $\operatorname{tax} \mathcal{T}(y)$. The taxable income $y$ is based on both labor income and capital income. We incorporate two features of the current U.S. tax code related to the taxation of health-related expenses into our definition of $y$. First, households can tax-exempt their medical expenses in excess of $7.5 \%$ of their income. Second, households buying group insurance can subtract the out-of-pocket group premium $\bar{p}$ from their taxable income.

We also assume a social welfare system, $T^{S I}$, which guarantees that a household will have a minimum consumption level at $\underline{c}$. This reflects the U.S. public transfer programs such as the Medically Needy part of Medicaid, food stamps, Supplemental Security Income (SSI), and transfers to finance uncompensated care.

All old individuals are retired. They receive Social Security benefits in the amount ss.

\section{Optimization problem}

The state variables of an old individual include liquid capital $\left(k \in \mathbb{K}=R^{+} \cup\{0\}\right)$ and health status $(h \in \mathbb{H}=\{1,2, \ldots, H\})$. The value function of the old can be written as follows:

$$
\begin{gathered}
\mathbf{V}^{o}(k, h)=\max _{c, k^{\prime}} u(c)+\beta \zeta^{o} E_{t} \mathbf{V}^{o}\left(k^{\prime}, h^{\prime}\right) \\
\text { s.t. } \quad k(1+r)+s s+T^{S I}=c+\zeta^{o} k^{\prime}+x\left(1-q^{\text {med }}(x)\right)+p^{\text {med }}+\mathcal{T}(y)
\end{gathered}
$$

where

$$
\begin{aligned}
T^{S I} & =\max \left(0, \underline{c}+x\left(1-q^{\text {med }}(x)\right)+\mathcal{T}(y)+p^{\text {med }}-s s-k(1+r)\right) \\
y & =\max (0, \widetilde{y}) \\
\widetilde{y} & =r k+s s-\max \left(0, x\left(1-q^{\text {med }}(x)\right)-0.075(r k+s s)\right)
\end{aligned}
$$

Equation (3) is the budget constraint. We assume that there is an actuarially-fair annuity market. Thus each retired individual needs to save only $\zeta^{o} k^{\prime}$ instead of $k^{\prime 10}$. Equation

\footnotetext{
${ }^{10}$ Alternatively, it can be assumed that accidental bequests are evenly distributed to all young agents. Since the distributed amount is small, it will not affect our results. However, the computational cost is
} 
(6) takes into account the tax-deductibility of medical expenses in excess of $7.5 \%$ of the total income. ${ }^{11}$

The state variables for a young individual include liquid capital $\left(k \in \mathbb{K}=R^{+} \cup\{0\}\right)$, health status $(h \in \mathbb{H}=\{1,2, \ldots, H\})$, idiosyncratic labor productivity $\left(z \in \mathbb{Z}=R^{+}\right)$, ESHI offer status $(g \in \mathbb{G}=\{0,1\})$, and an index of health insurance status $(i \in \mathbb{I}=\{-2,-1,0,1,2, \ldots, H\})$.

Each period an individual chooses his consumption $(c)$, saving $\left(k^{\prime}\right)$, and health insurance status for the next period $\left(i^{H}\right)$. Depending on one's Medicaid eligibility, ESHI offer and insurance status, he can choose not to buy any insurance $(N B)$, buy a guaranteed renewable contract $(B G R)$, renew the existing guaranteed renewable contract $(R G R)$, buy a standard individual policy $(B I)$, buy a group insurance $(B G)$, or enroll in Medicaid $(B M)$. We summarize the insurance choices as follows.

- If a household currently has a guaranteed renewable contract, $i=\{1,2,3, . ., H\},{ }^{12}$ $\{B G R, R G R, B I, B G, B M\}$ if $g=1$ and eligible for Medicaid

$$
\begin{aligned}
& i^{H}=\{B G R, R G R, B I, B M\} \quad \text { if } g=0 \text { and eligible for Medicaid } \\
& \{N B, B G R, R G R, B I, B G\} \quad \text { if } g=1 \text { and not eligible for Medicaid } \\
& \{N B, B G R, R G R, B I\} \quad \text { if } g=0 \text { and not eligible for Medicaid }
\end{aligned}
$$

- If a household does not have a guaranteed renewable contract, $i=\{-2,-1,0\}$,

$$
\begin{aligned}
& \{B G R, B I, B G, B M\} \quad \text { if } g=1 \text { and eligible for Medicaid } \\
& i^{H}=\{B G R, B I, B M\} \quad \text { if } g=0 \text { and eligible for Medicaid } \\
& \{N B, B G R, B I, B G\} \quad \text { if } g=1 \text { and not eligible for Medicaid } \\
& \{N B, B G R, B I\} \quad \text { if } g=0 \text { and not eligible for Medicaid }
\end{aligned}
$$

The value function of a working-age household can be written as follows:

$$
\begin{gathered}
\mathbf{V}^{y}(k, h, z, g, i)=\max _{c, k^{\prime}, i^{H}} u(c)+\beta \zeta^{y} E \mathbf{V}^{y}\left(k^{\prime}, h^{\prime}, z^{\prime}, g^{\prime}, i^{\prime}\right)+\beta\left(1-\zeta^{y}\right) E \mathbf{V}^{o}\left(k^{\prime}, h^{\prime}, i^{\prime}\right) \\
\text { s.t. } \quad k(1+r)+\widetilde{w} z+T^{S I}=c+k^{\prime}+x(1-q(i, x))+P\left(h, i, i^{H}\right)+\mathcal{T}(y)
\end{gathered}
$$

higher since one needs to wait until the convergence of total bequests to get the invariant distribution.

${ }^{11}$ The problem of a newly retired household is slightly different from a retired household since he is still covered by his pre-retirement insurance. The difference lies in the state variables and the out-of-pocket medical expenditure. For the newly retired, the state variables are $\{k, h, i\}$; and in the budget constraint $x\left(1-q^{\text {med }}(x)\right)$ is replaced by $x(1-q(i, x))$.

${ }^{12}$ Note that if a household is eligible for Medicaid he cannot stay uninsured because Medicaid is free. 
where

$$
\begin{aligned}
& \widetilde{w}=\left\{\begin{array}{lll}
w & ; & \text { if } g=0 \\
w-c_{E} & ; & \text { if } g=1
\end{array}\right\} \\
& P\left(h, i, i^{H}\right)=\left\{\begin{array}{lll}
0 & ; & \text { if } i^{H}=N B \text { or } B M \\
p^{I}(h) & ; & \text { if } i^{H}=B I \\
p^{G R}(h) & ; & \text { if } i^{H}=B G R \\
p^{G R}(i) & ; & \text { if } i^{H}=R G R \\
\bar{p} & ; & \text { if } i^{H}=B G
\end{array}\right\} \\
& y=\max (0, \widetilde{y}) \\
& \widetilde{y}=\left\{\begin{array}{ll}
\widetilde{w} z+r k-\max (0, x(1-q(i, x))-0.075(\widetilde{w} z+r k)) & ; \quad \text { if } i^{H} \neq B G \\
\widetilde{w} z+r k-\max (0, x(1-q(i, x))-0.075(\widetilde{w} z+r k))-\bar{p} \quad ; \quad \text { if } i^{H}=B G
\end{array}\right\} \\
& T^{S I}=\max (0, \underline{c}+x(1-q(i, x))+\mathcal{T}(y)-\widetilde{w} z-k(1+r)) \\
& i^{\prime}=\left\{\begin{array}{cll}
-2 & ; & \text { if } i^{H}=N B \\
-1 & ; & \text { if } i^{H}=B M \\
0 & ; & \text { if } i^{H}=\{B I, B G\} \\
i & ; & \text { if } i^{H}=R G R \\
h & ; & \text { if } i^{H}=B G R
\end{array}\right\}
\end{aligned}
$$

The conditional expectation on the right-hand side of equation (7) is over $\left\{h^{\prime}, z^{\prime}, g^{\prime}\right\}$. The second equation is the budget constraint. In equation (9), $w$ is the wage per effective labor unit. If a household has an ESHI offer, then the employer partly pays the premium. In order to break even, the employer deducts $c_{E}$ from the wage per effective labor unit to get an adjusted wage $\widetilde{w}$. Equation (12) reflects the tax deductibility of the ESHI premium and medical expenses exceeding $7.5 \%$ of the income. Equation (14) maps the current health insurance status and health insurance choices into the next period health insurance status. The income eligibility of the Medicaid program requires that

$$
k(1+r)+\widetilde{w} z-x(1-q(i, x)) \leq y^{p u b} .
$$


To simplify the notations, we denote the space of a household' state variables by $\mathbb{S}$ : $\mathbb{S} \equiv \mathbb{K} \times \mathbb{H} \times \mathbb{Z} \times \mathbb{G} \times \mathbb{I}$ for young individuals, $\mathbb{S} \equiv \mathbb{K} \times \mathbb{H} \times \mathbb{I}$ for just-retired individuals, and $\mathbb{S} \equiv \mathbb{K} \times \mathbb{H}$ for retirees. Let $\mathbf{s} \in \mathbb{S}$ and denote by $\Gamma^{y}(\mathbf{s})$ and $\Gamma^{o}(\mathbf{s})$ the measure of young and retired people correspondingly.

\subsection{Production sector}

There are two stand-in firms that act competitively. Their production functions are Cobb-Douglas, $A K^{\alpha} L^{1-\alpha}$, where $K$ and $L$ are the aggregate capital and labor and $A$ is the total factor productivity. The first stand-in firm offers ESHI to its workers, while the second does not ${ }^{13}$. Under the competitive market assumption, the second firm pays each employee his marginal product of labor. Since capital is freely allocated between the two firms, the Cobb-Douglas production function implies that the capital-labor ratios of both firms are the same. Consequently we have ${ }^{14}$

$$
\begin{gathered}
r=\alpha A K^{\alpha-1} L^{1-\alpha}-\delta, \\
w=(1-\alpha) A K^{\alpha} L^{-\alpha},
\end{gathered}
$$

where $\delta$ is the depreciation rate.

The first firm has to partially finance health insurance premiums for its employees and these costs are fully passed on to the employees via a wage reduction. In specifying this wage reduction we follow Jeske and Kitao (2009). The first firm subtracts an amount of $c_{E}$ from the marginal product per effective labor. The total wage reduction of each

\footnotetext{
${ }^{13}$ An alternative setup is that there are two islands, one offers ESHI and the other does not. Workers are stochastically allocated between the two islands but there are no frictions in the capital market. Inside each island, the labor market is competitive.

${ }^{14}$ Define $\left\{K_{1}, L_{1}\right\}$ and $\left\{K_{2}, L_{2}\right\}$ as the aggregate capital and labor in firms 1 and 2. Since capital can move freely between the firms, the Cobb-Douglas production implies $r+\delta=\alpha A\left(\frac{K_{1}}{L_{1}}\right)^{\alpha-1}=$ $\alpha A\left(\frac{K_{2}}{L_{2}}\right)^{\alpha-1}$. Next we can write

$$
\frac{K}{L}=\frac{K_{1}+K_{2}}{L_{1}+L_{2}}=\frac{\frac{K_{1}}{L_{1}}+\frac{K_{2}}{L_{2}} \frac{L_{2}}{L_{1}}}{1+\frac{L_{2}}{L_{1}}}=\frac{K_{1}}{L_{1}}
$$
}

The last equality uses the fact that $\frac{K_{1}}{L_{1}}=\frac{K_{2}}{L_{2}}$. 
employee with an ESHI offer is $c_{E} z$. The zero profit condition implies

$$
c_{E}=\frac{\psi p\left(\int \mathbf{1}_{\left\{i^{H}=B G\right\}} \Gamma^{y}(s)\right)}{\int \mathbf{1}_{\{g=1\}} z \Gamma^{y}(\boldsymbol{s})},
$$

where $\mathbf{1}_{\{\cdot\}}$ is a function that is equal to one if its argument is true, otherwise the function is equal to zero.

\subsection{Private health insurance sector}

We model the health insurance sector under the following assumptions. First, both individual and group insurance markets are competitive, implying zero expected profit for each insurance contract. Second, there are administrative costs associated with issuing an insurance policy, which are proportional to the total value of the contract. Third, health insurance companies can observe only the current health status of an individual. ${ }^{15}$

The zero profit condition implies that the premium for a standard one-period insurance contract is equal to the expected discounted medical costs covered by an insurance company multiplied by the administrative load $\left(\gamma^{I}\right)$ :

$$
p^{I}(h)=(1+r)^{-1} \gamma^{I} E M(h) .
$$

Here $E M(h)$ is the expected medical expenses of an individual with health status $h$ covered by an insurance company:

$$
E M(h)=\sum_{h^{\prime}} x\left(h^{\prime}\right) q\left(0, x\left(h^{\prime}\right)\right) G^{y}\left(h^{\prime} \mid h\right)
$$

The price of a newly issued guaranteed renewable contract depends on the current health status of an individual. To determine the premium, an insurer needs to assign a probability to an event that an individual will continue to renew the contract. Consider

\footnotetext{
${ }^{15}$ For standard one-period insurance contracts only health status matters for pricing. For guaranteed renewable contracts an additional factor that affects pricing is the probability that the contract will be renewed in the future. This probability depends not only on health, but also on other state variables, in particular assets and labor income. We do not allow prices to be conditioned on assets or labor income because these variables are difficult for insurance companies to verify.
} 
an individual with health status $h_{t}$ who chooses to buy a new guaranteed renewable contract in period $t$. Denote by $\pi_{t+j}\left(h_{t+j} \mid h_{t}\right)$ an insurer's belief that this individual will continue to renew the same insurance contract every period up to a period $t+j$ when his health status becomes $h_{t+j}$. The zero profit condition allows us to write the premium of a new guaranteed renewable contract as follows:

$$
p^{G R}\left(h_{t}\right)=p^{I}\left(h_{t}\right)+\sum_{j=1}^{\infty} \frac{1}{(1+r)^{j}} \sum_{h_{t+j}=1}^{H} \pi_{t+j}\left(h_{t+j} \mid h_{t}\right)\left(p^{I}\left(h_{t+j}\right)-p^{G R}\left(h_{t}\right)\right) .
$$

The first term on the right hand side is the premium for a standard insurance contract that covers medical expenses in the next period. The second term is the extra payment for the option to renew the contract in the future. It arises because an insurance company will not be able to readjust the price in the future even if an individual's health deteriorates.

The beliefs of the insurer $\pi_{t+j}\left(h_{t+j} \mid h_{t}\right)$ should be consistent with a household's optimal decisions in equilibrium. Denote the measure of young people with health status $h_{t}$ who choose to buy a new guaranteed renewable contract in period $t$ by $\Gamma^{y}\left(h_{t}, i_{t}^{H}=B G R\right)$. Denote by $\mathcal{F}\left(h_{t+j}, i_{t+j}^{H}=R G R \| h_{t}, i_{t}^{H}=B G R\right)$ the measure of those people in this group who have been renewing the same contract every period from period $t$ to period $t+j$ when their health becomes $h_{t+j}$. Thus $\pi_{t+j}\left(h_{t+j} \mid h_{t}\right)$ can be defined as

$$
\pi_{t+j}\left(h_{t+j} \mid h_{t}\right)=\frac{\mathcal{F}\left(h_{t+j}, i_{t+j}^{H}=R G R \| h_{t}, i_{t}^{H}=B G R\right)}{\Gamma^{y}\left(h_{t}, i_{t}^{H}=B G R\right)} .
$$

The premium in the group insurance market does not depend on the health status of individuals. ${ }^{16}$ Using the zero profit condition, the premium can be written as a weighted average of the expected covered medical costs of participating employees multiplied by the administrative load $\left(\gamma^{G}\right)$.

$$
p=(1+r)^{-1} \gamma^{G} \frac{\int \mathbf{1}_{\left\{i^{H}=B G\right\}} \times E M(h) \Gamma^{y}(\boldsymbol{s})}{\int \mathbf{1}_{\left\{i^{H}=B G\right\}} \Gamma^{y}(\boldsymbol{s})},
$$

\footnotetext{
${ }^{16}$ The U.S. regulation prohibits employers from charging employees with different health-related characteristics different insurance premiums.
} 


\subsection{Government constraint}

We assume that the government runs a balanced budget. This implies:

$$
\int \mathcal{T}(y) \Gamma^{y}(\boldsymbol{s})+\int \mathcal{T}(y) \Gamma^{o}(\boldsymbol{s})=\int\left(s s+x q^{\text {med }}(x)-p^{\text {med }}\right) \Gamma^{o}(\boldsymbol{s})+\int T^{S I} \Gamma^{y}(\boldsymbol{s})+\int T^{S I} \Gamma^{o}(\boldsymbol{s})
$$

The left-hand side is the total income tax. The first term on the right-hand side is the net expenditure on Social Security and Medicare systems for the old. The last two terms are the costs of running the means-tested transfer program, i.e. to keep households above the consumption minimum floor.

We define the competitive equilibrium of the economy in the Appendix.

\section{Data and Calibration}

\subsection{Data}

We calibrate the model using the Medical Expenditure Panel Survey (MEPS) dataset. The MEPS collects detailed records on demographics, income, medical costs and insurance for a nationally representative sample of households. It consists of two-year overlapping panels. We use eight waves of the MEPS, from 1999 to 2007.

The MEPS links people into one household based on eligibility for coverage under a typical family insurance plan. This Health Insurance Eligibility Unit (HIEU) defined in the MEPS dataset corresponds to our definition of a household. All statistics we use were computed for the head of the HIEU, i.e. we use individual-level data where each individual is the head of a household. We define the head as the person who has the highest income in the HIEU. A different definition of the head (based on gender) does not give significantly different results. We use longitudinal weights provided in the MEPS to compute all the statistics. Given that all individuals are observed for at most two years, we pool together all eight waves of the MEPS. Since each wave is a representation of the population in each year, the weight of each individual was divided by eight in the pooled 
sample.

In our sample we include all non-student heads whose age is at least 20 years old and whose labor income (to be defined later) is non-negative. The sample size for each wave is presented in Table 1. We use 2003 as a base year. All level variables were normalized to the base year using the Consumer Price Index (CPI).

\begin{tabular}{|c|c|c|c|c|c|c|c|c|c|}
\hline Panel & $99 / 00$ & $00 / 01$ & $01 / 02$ & $02 / 03$ & $03 / 04$ & $04 / 05$ & $05 / 06$ & $06 / 07$ & Total \\
\hline Obs. & 4,954 & 4,017 & 8,248 & 6,244 & 6,464 & 6,417 & 6,200 & 6,656 & 49,200 \\
\hline
\end{tabular}

Table 1: Number of observations in eight waves of MEPS (1999-2007)

When measuring the insurance status in the data, we use the following approach. In the MEPS the question about the source of insurance coverage was asked retrospectively for each month of the year. We define a person as having employer-based insurance if he reports having ESHI for at least eight months during the year (variables PEGJAPEGDE). The same criteria are used when defining public insurance (variables PUBJAPUBDE) and individual insurance status (variables PRIJA-PRIDE). ${ }^{17}$ In addition, we assume that a person has an ESHI offer if he reports having an offer in at least two out of three interview rounds during a year (variables OFFER31x, OFFER42x, OFFER53x).

\subsection{Demographics, preferences and technology}

The period in the model is one year. Young agents are born at age 20 and stay young on average 45 years, so the probability to stay young, $\zeta^{y}$, is set to $44 / 45$. The survival probability of an old individual $\zeta^{o}$ is set to make the fraction of the old in the population equal to $20 \%$; thus $1-\zeta^{o}=4\left(1-\zeta^{y}\right)$. To keep the total measure of population equal to one, the measure of newborns in every period is set to $\frac{\left(1-\zeta^{y}\right)\left(1-\zeta^{o}\right)}{2-\zeta^{y}-\zeta^{o}}$.

\footnotetext{
${ }^{17}$ For those few individuals who switch the source of coverage during the year, we define insurance status in the following way. If a person has both ESHI and individual insurance in one year, and each coverage lasted for less than eight months but with a total duration of coverage of more than eight months, we classify this person as individually insured. Likewise, when a person has a combination of individual and public coverage that altogether lasts for more than eight months, we define that individual as having public insurance. Our results do not change significantly if we change the cutoff point to 6 or 12 months.
} 
The risk aversion parameter $\sigma$ is equal to 3 which is in the range commonly used in the macroeconomic literature. The discount factor $\beta$ is calibrated to match the aggregate capital output ratio of 3.0 .

The Cobb-Douglas function parameter $\alpha$ is set to 0.33 which corresponds to the capital income share in the U.S. The annual depreciation rate $\delta$ is calibrated to achieve the interest rate of $4.0 \%$ in the baseline economy. The total factor productivity $A$ is normalized to make the average labor income equal to one in the baseline model.

\subsection{Joint process of health, labor income, and ESHI offer}

The medical expenses in our model correspond to the total amount paid for the health care services (variable: TOTEXP). This includes both out-of-pocket payments and payments made by insurance companies but it does not include over-the-counter drugs. In our model there is a one-to-one mapping between medical expenses and health status. We categorize medical expenses into five bins and each bin corresponds to a different health status (Table 2).

\begin{tabular}{lccccc}
\cline { 2 - 5 } & $h=1$ & $h=2$ & $h=3$ & $h=4$ & $h=5$ \\
\hline medical expenses (percentile) & $<30^{t h}$ & $30^{t h}-60^{t h}$ & $60^{t h}-90^{t h}$ & $90^{t h}-99^{t h}$ & $>99^{t h}$ \\
\hline
\end{tabular}

Table 2: Health status and medical expenses

The average amount of medical expenses corresponding to each health status are ( $0.001,0.016,0.075,0.318,1.483)$ for young households and $(0.021,0.083,0.251,0.917,2.317)$ for retired households. These numbers are based on the medical expenses in the 2003/2004 wave normalized by the average labor income $(\$ 35,624)$.

To construct a transition matrix for health status, we compute the fraction of households moving from one bin to another. ${ }^{18}$ The resulting transition matrices for young

\footnotetext{
${ }^{18}$ We assume that medical shocks follow a Markov process since the MEPS allows us to observe only two consecutive periods of medical expenses for each individual. The implied first and second autocorrelations of total medical expenses are 0.37 and 0.16 . French and Jones (2004) provide a detailed examination of health costs in the Health and Retirement Survey (HRS) dataset and report that the first and second autocorrelations are equal to 0.45 and 0.34 correspondingly. It is important to point out that these numbers should be compared with caution for the following reasons. First, French and Jones's
} 
households, $G^{y}\left(h^{\prime} \mid h\right)$, and for retired households, $G^{o}\left(h^{\prime} \mid h\right)$, are reported in the Appendix.

We define labor income as a sum of wages (variable WAGEP) and $75 \%$ of income from business (variable BUSNP). We categorize labor income into five quintiles $(5 \times 20 \%)$. The labor income level in each quintile is based on the value for the 2003/2004 wave normalized by the average income. These numbers are $0.091,0.477,0.802,1.226$, and 2.417

The dashed lines in Panels $(a)$ and $(b)$ in Figure 1 show the relationship between labor income and medical expenses/health observed in the data. The hump shape in Panel $(a)$ can be explained by the life-cycle profile of labor income. Our model does not have an age dimension so the age profile of labor income is partially captured by health status. In the data, households in good health $(h=1)$ are more likely to be young, while those in bad health $(h=4$ or $h=5)$ are more likely to be near retirement. These two groups tend to have lower incomes than the middle-aged households.

Panel (b) also shows that the average medical expenses of households in the first income quintile are two times higher than the average medical expenses of the high income group. This pattern is driven by two facts. First, the distribution of medical expenses is highly skewed: the medical expenses of people with $h=5$ is more than four times higher than the medical expenses of those with $h=4$. Second, households with serious health problems, $h=5$, are more likely to experience a very low income shock.

When constructing a joint Markov process of labor income and health status, our goal is to capture the above pattern. To do this we divide our sample into four subsamples based on the health status in the second year of each wave. The first, second, and third subsamples include households whose health status in the second year equals 1, 2, and 3 respectively. The fourth subsample include households whose health status in the second year equals 4 or 5 . Then we construct a transition matrix of labor income for each subsample by calculating the fraction of households who move from

estimates are based on out-of-pocket medical expenses while our results are based on total medical expenses. Second, the HRS includes only people above age 50 while our estimates include young people. 
a) labor income by health

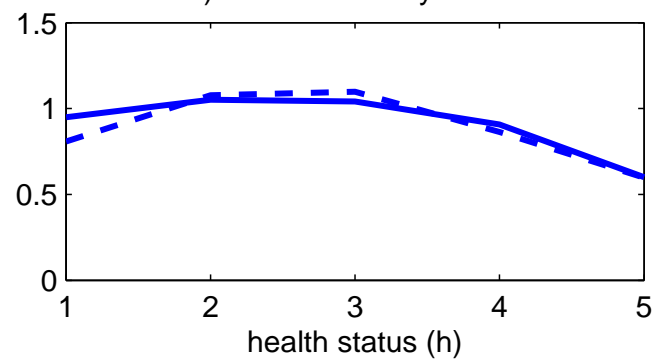

c) offer rate by health status

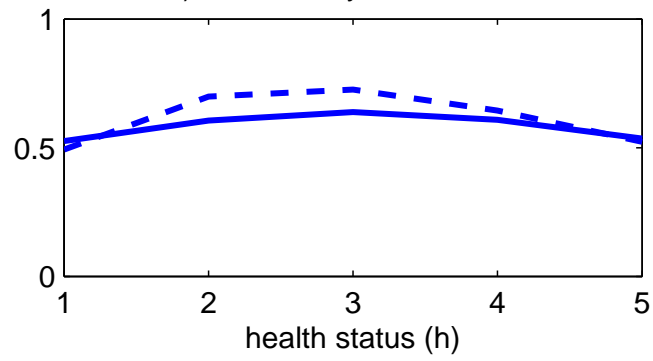

e) labor income by health

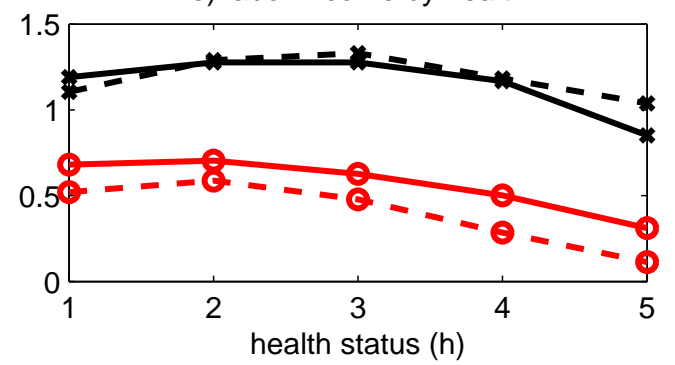

b) medical expenses by income quintile

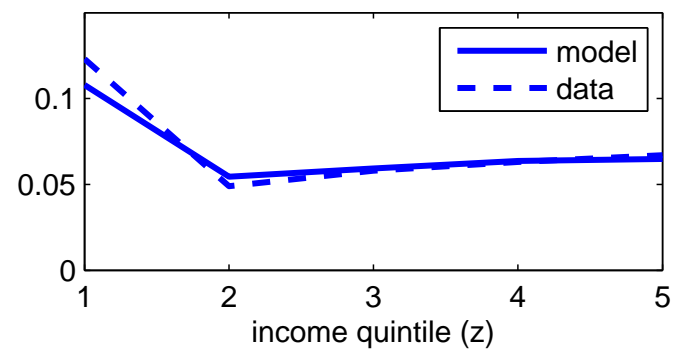

d) offer rate by income quintile
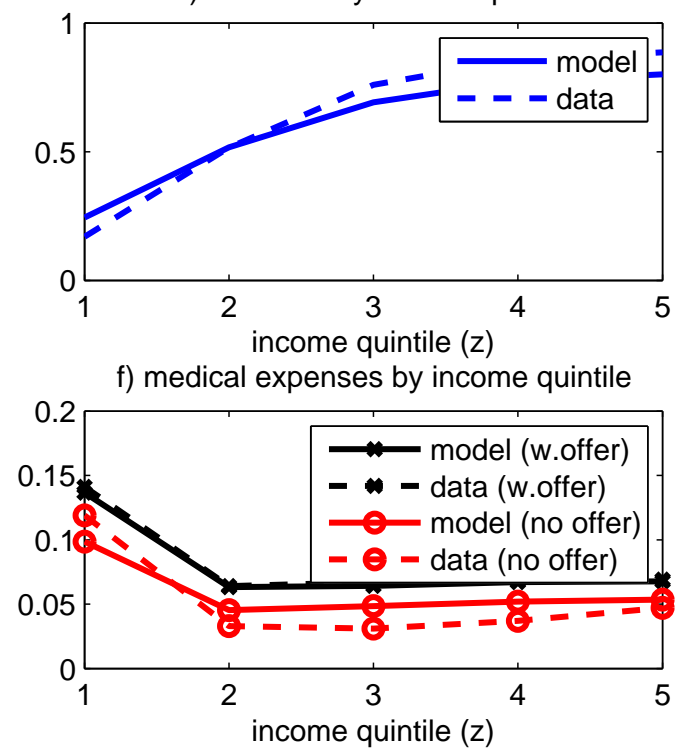

Figure 1: Relationship between ESHI offer, labor income, and medical expenses

one quintile to another. The resulting four transition matrixes capture the dynamics of labor income conditional on health shock in the second period, and are denoted as $Q\left(z^{\prime} \mid z, h^{\prime}=1\right), Q\left(z^{\prime} \mid z, h^{\prime}=2\right), Q\left(z^{\prime} \mid z, h^{\prime}=3\right)$, and $Q\left(z^{\prime} \mid z, h^{\prime}=4\right)$. Due to the small sample size, we cannot get the transition matrix conditional on $h^{\prime}=5$ directly. So we define

$$
Q\left(z^{\prime} \mid z, h^{\prime}=5\right)=a \times Q\left(z^{\prime} \mid z, h^{\prime}=4\right)+(1-a) \times D ; \quad 0 \leq a \leq 1,
$$

where $D$ is a $5 \times 5$ matrix with the first column equal to one and the remaining columns equal to zero. If $a=1, Q\left(z^{\prime} \mid z, h^{\prime}=5\right)=Q\left(z^{\prime} \mid z, h^{\prime}=4\right)$. But if $a=0, Q\left(z^{\prime} \mid z, h^{\prime}=5\right)=$ $D$, meaning that the income of those households who have serious health problems drops to the level of the lowest income quintile. In our calibration, we choose $a$ to make the average labor income of those with $h=5$ match the data as shown in Panel $(a)$ of Figure 
1.

The joint transition matrix of health status and labor income is constructed by combining the transition matrix of health status, $G^{y}\left(h^{\prime} \mid h\right)$, with the conditional transition matrix of labor income $Q\left(z^{\prime} \mid z, h^{\prime}\right)$. The advantage of this approach is that the conditional expected medical expenses depend only on the current health status. This dramatically simplifies the computation since we can compute the premiums of standard one-period insurance directly from $G^{y}\left(h^{\prime} \mid h\right) \cdot{ }^{19}$

The dashed line in Panel $(d)$ in Figure 1 shows that there is a strong correlation between the probability of getting access to ESHI and labor income. We assume that the probability of getting an ESHI offer is a logistic function:

$$
\operatorname{Prob}_{t}=\frac{\exp \left(u_{t}\right)}{1+\exp \left(u_{t}\right)}
$$

where variable $u_{t}$ is an odds ratio that takes the following form:

$$
u_{t}=\eta_{0}+\eta_{1} D_{g_{t-1}}+\eta_{h} D_{h_{t}}+\eta_{z} D_{z_{t}}+\eta_{\text {year }} D_{\text {year }},
$$

where $D_{g_{t-1}}$ is a dummy variable for an ESHI offer in period $t-1, D_{h_{t}}$ and $D_{z_{t}}$ are the sets of dummy variables for health status and income quintile in period $t$, and $D_{\text {year }}$ is a set of dummy variables for each year.

To calibrate the joint distribution $\{h, z, g\}$ of newborns, we use the empirical joint distribution of households aged 20-35 from the data. This allows us to approximate the life-cycle features absent from our model. In particular, an important characteristic of a life-cycle model is an increasing age profile of medical expenses and labor income. In our calibration, newborns are clustered around relatively low medical expenses and labor productivity. Given the persistence of the processes for medical shocks and productivity, young people in our model are slowly moving up the medical expenses and labor income

\footnotetext{
${ }^{19}$ If the conditional expected medical expenses also depend on the current labor income, say $E\left(x^{\prime} \mid x, z=1\right) \neq E\left(x^{\prime} \mid x, z=2\right)$, and the insurance company does not observe $z$, then the premiums of standard one-period contracts will depend on households' insurance decisions and the equilibrium distribution of households.
} 
ladders. The average medical expense as a fraction of the average labor income in our model is $7.1 \%$ for young people and $20.0 \%$ for old people, compared with $7.3 \%$ and $20.4 \%$ in the MEPS. For newborns, the fraction of the average medical expense in the average labor income constitutes $4.6 \%$ comparing to $5.2 \%$ for people aged 20-35 in the MEPS.

Figure 1 compares our simulations of $\{h, z, g\}$ with the data (simulations are plotted with the solid lines). Overall, we are able to match the key features of the data well. However, the simulated offer rate $(59.1 \%)$ is slightly lower than in the data $(64 \%) .{ }^{20}$

\subsection{Insurance policies}

We use the MEPS to find the fraction of medical costs covered by an average insurance policy. We estimate the following equation

$$
\text { InsCov }=\beta_{0}+\beta_{1} x+\beta_{2} x^{2}+\Theta D_{\text {year }}
$$

separately for private insurance, Medicaid, and Medicare. InsCov is medical expenses paid by insurance (variables: TOTPRV,TOTMCD,TOTMCR). We include only people with positive medical expenses when estimating this regression. Then we use our estimates to compute the fraction of medical expenses covered by insurance for each health status and truncate it to be between 0 and 1 . Table 3 reports the results for each type of insurance.

\begin{tabular}{|l|c|c|c|c|c|}
\hline & $h=1$ & $h=2$ & $h=3$ & $h=4$ & $h=5$ \\
\hline Medicaid: $q(-1, x)$ & 1.00 & 1.00 & 0.70 & 0.52 & 0.50 \\
Private insurance: $q(i, x)$ for $i=\{0,1, . ., 5\}$ & 0.00 & 0.40 & 0.71 & 0.78 & 0.81 \\
Medicare: $q^{\text {med }}(x)$ & 0.00 & 0.35 & 0.56 & 0.64 & 0.65 \\
\hline
\end{tabular}

Table 3: Fraction of medical expenses covered by insurance

\footnotetext{
${ }^{20}$ This mismatch mostly arises from the absence of educational heterogeneity in our model. As shown in Pashchenko and Porapakkarm (2013), people with low educational attainment have significantly lower probability of getting access to ESHI.
} 


\subsection{Government constraint}

In calibrating the tax function $\mathcal{T}(y)$ we use a nonlinear relationship specified and estimated by Gouveia and Strauss (1994):

$$
\mathcal{T}(y)=a_{0}\left[y-\left(y^{-a_{1}}+a_{2}\right)^{-1 / a_{1}}\right] .
$$

Here $a_{0}$ controls the marginal tax rate levied on people with the highest income, $a_{1}$ determines the progressivity of the tax code, and $a_{2}$ is a scaling parameter. We set $a_{0}$ and $a_{1}$ to the original estimates of Gouveia and Strauss (0.258 and 0.768 correspondingly). Parameter $a_{2}$ is used to balance the government budget.

The consumption minimum floor $\underline{c}$ in the baseline economy was calibrated so that the fraction of households with assets less than $\$ 5,000$ in the model is the same as in the data. Based on the 1989-2001 Survey of Consumer Finance (SCF) dataset this fraction is $20.0 \%$ (Kennickell, 2003). To match this fraction, $\underline{c}$ is set to 0.92 of the Federal Poverty Line (FPL), or $\$ 8,807$.

The Social Security replacement rate is set to $45 \%$ of the average labor income. This number is obtained by applying the Social Security benefit formula to the average labor earnings profile.

\subsection{Medicaid and private insurance}

The Medicaid eligibility rules differ from state to state. We set $y^{p u b}$ to $48.0 \%$ of the FPL, or $\$ 4,595$, to match the fraction of people insured by Medicaid.

In our baseline model, we assume that only standard one-year contracts are offered in the individual market. To match the fraction of those buying individual insurance, we set the administrative load of an individual insurance policy $\gamma^{I}$ to 1.208 .

The administrative load for the group insurance $\gamma^{G}$ is set to 1.11 (Kahn et al., 2005). We set the share of health insurance premium paid by the firm $(\psi)$ to $83.0 \%$. This number is consistent with the data in which the premiums of group insurance paid by 
employers range from $77 \%$ to $89 \%$ (Sommers, 2002).

\subsection{Performance of the baseline model}

Tables 4 and 5 summarize the parameters used in our baseline model. Table 6 reports the fraction of non-elderly adults with different insurance statuses and the numerical results from the baseline model. The model slightly underestimates the fraction of people with ESHI because our calibrated offer rate is lower than that in the data. As a result the fraction of the uninsured is slightly overestimated.

\begin{tabular}{|l|c|c|c|}
\hline Parameter name & Notation & Value & Source \\
\hline Risk aversion & $\sigma$ & 3 & - \\
Cobb-Douglas parameter & $\alpha$ & 0.33 & Capital share in output \\
Tax function parameters & $a_{0}$ & 0.258 & Gouveia and Strauss (1994) \\
& $a_{1}$ & 0.768 & Gouveia and Strauss (1994) \\
Social Security replacement rates & $s s$ & $45 \%$ & - \\
Group insurance loads & $\gamma^{G}$ & 1.11 & Kahn et al. (2005) \\
Employer's contribution & $\psi$ & 0.83 & Sommers $(2002)$ \\
Medicare premium & $p^{\text {med }}$ & $\$ 1,071$ & Total premiums $=2.11 \%$ of $Y$ \\
\hline
\end{tabular}

Table 4: Parameters set outside the model

\begin{tabular}{|l|c|c|c|}
\hline Parameter name & Notation & Value & Target \\
\hline Discount factor & $\beta$ & 0.908 & $\frac{K}{Y}=3$ \\
Depreciation rate & $\delta$ & 0.07 & $r=0.04$ \\
Individual insurance loads & $\gamma^{I}$ & 1.21 & $\%$ of individual insurance $=8.2 \%$ \\
Medicaid's income eligibility & $y^{p u b}$ & $\$ 4,595$ & $\%$ of public insurance $=9.1 \%$ \\
Consumption floor & $\underline{c}$ & $\$ 8,807$ & $\%$ with assets $<\$ 5,000=20 \%$ \\
\hline
\end{tabular}

Table 5: Parameters used to match some targets

\begin{tabular}{ccccc} 
& uninsured & public ins & individual ins & ESHI \\
\hline data & $21.45 \%$ & $9.10 \%$ & $8.20 \%$ & $61.30 \%$ \\
model & $25.4 \%$ & $9.10 \%$ & $8.20 \%$ & $57.30 \%$ \\
\hline
\end{tabular}

Table 6: Percentage of non-elderly adults with different insurance status (2003/2004)

To evaluate the performance of our baseline model, we use health insurance statistics 
not targeted by our calibration. Figures 2 and 3 show the decomposition of health insurance status along the dimensions of labor income and health status. Our model is able to replicate the insurance statistics for people in different income and health categories.

\section{$5 \quad$ Results and discussions}

This section discusses how the baseline economy changes once guaranteed renewable contracts are introduced. We provide an analysis based on the open economy case, i.e. we fix the interest rate and the wage but allow all insurance prices to adjust in equilibrium. $^{21}$

\section{$5.1 \quad$ Effects on premiums}

Figure 4 compares the premium for a newly issued guaranteed renewable contract with that for a standard one in the new steady state. Guaranteed renewable contracts are more expensive due to the extra payment for renewability. The difference in prices between the two types of contracts declines as health status deteriorates. For example, for the healthiest group, the premium for a guaranteed renewable contract is almost three times higher than that for a standard contract. At the other extreme, for people in the worst health status, the premiums for guaranteed renewable and standard insurance are the same. For this group of people health status cannot deteriorate any further, so the price of a guaranteed renewable contract does not include the extra payment for renewability.

In order to understand how well guaranteed renewable contracts provide protection against reclassification risk, Figure 5 compares premiums for standard contracts with the average premiums for guaranteed renewable contracts, including those already in force for at least one period. An important observation is that, on average, people who hold guaranteed renewable contracts face insurance premiums that are almost independent

\footnotetext{
${ }^{21}$ We do this to isolate the pure effect of providing insurance against reclassification risk from the effect of the change in the aggregate capital. For the closed economy case, the aggregate capital decreases slightly by $0.4 \%$.
} 

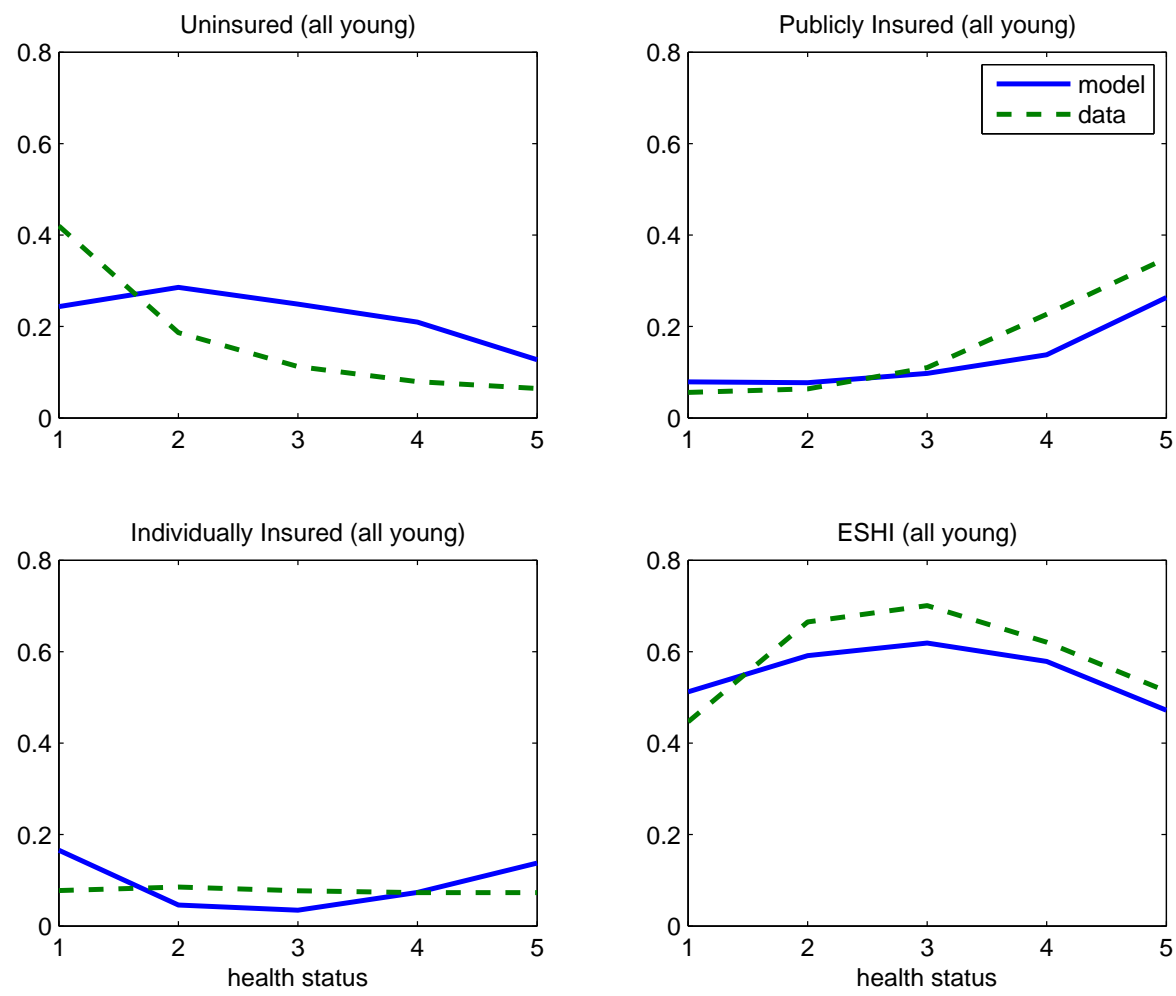

Figure 2: Insurance decision by health status (baseline model)
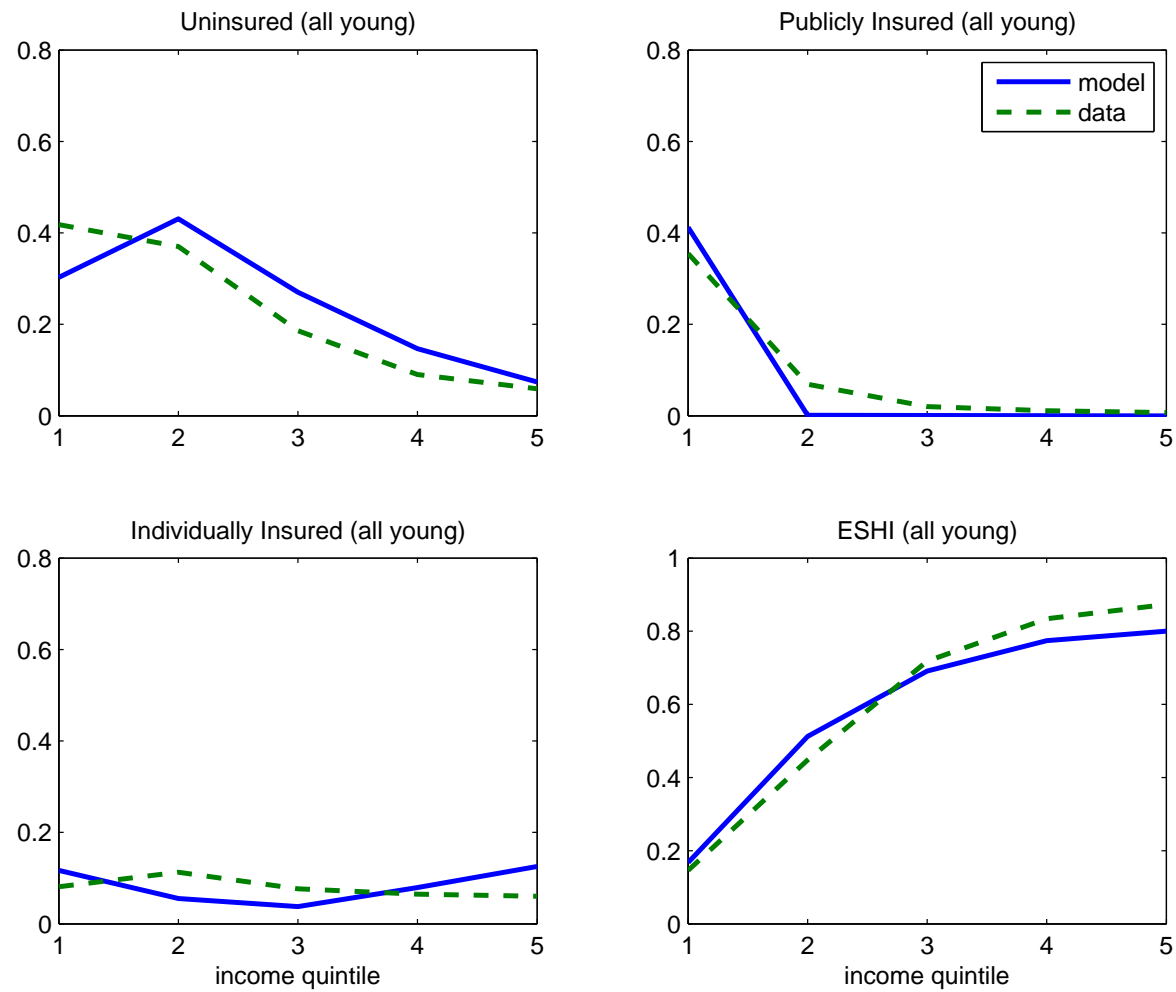

Figure 3: Insurance decision by labor income (baseline model) 
of their health status. This happens because most people initiate these contracts when they are healthy and later they face low premiums even if their health becomes worse. In contrast, people who buy standard contracts face a steep increase in their premiums once their health status deteriorates. This implies that a guaranteed renewable contract is a good way to eliminate the risk of premium fluctuations.

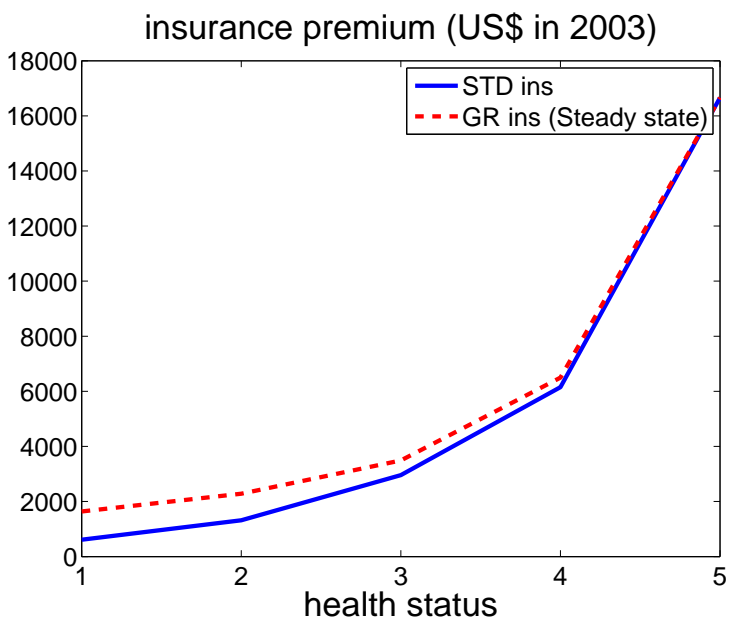

Figure 4: Premiums for new contracts

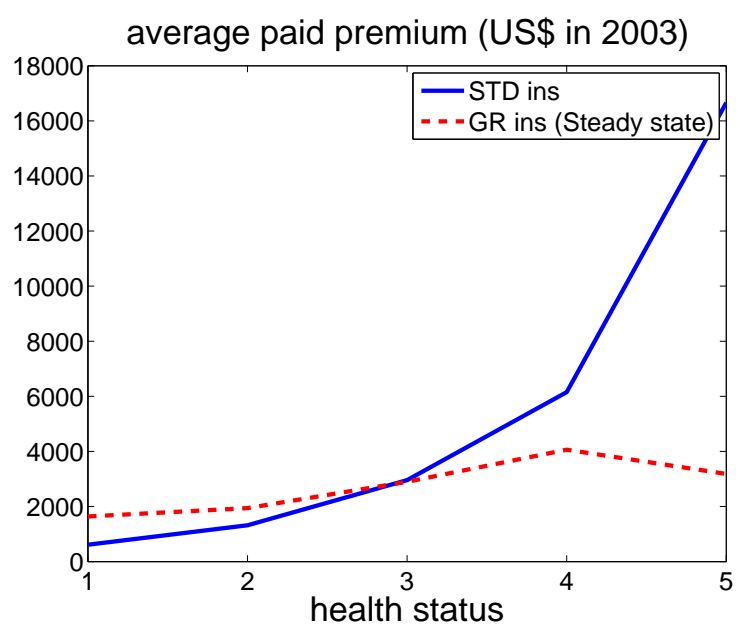

Figure 5: Average premiums for existing contracts

\subsection{Effects on health insurance decisions}

Table 7 shows how households' insurance purchasing decisions change after guaranteed renewable contracts are introduced. The fraction of uninsured in the new steady state noticeably decreases from $25.4 \%$ to $19.4 \%$. The fraction of people with individual insurance increases from $8.2 \%$ to $14.2 \%$, most of whom $(9.8 \%)$ hold guaranteed renewable contracts.

Figures 6 and 7 show the decomposition of health insurance decisions by income quintile and health status. Figure 6 shows that once guaranteed renewable contracts become available, participation in the individual market increases for people in both good and bad health, meaning that risk-sharing increases. More specifically, the percentage of uninsured among people with the worst health status decreases from $12.7 \%$ to $9.3 \%$, while for people with the best health status this number goes down from $24.3 \%$ to $22.4 \%$. 


\begin{tabular}{|l|c|c|}
\hline & Baseline & +GR contracts \\
\hline Uninsured (\%) & 25.4 & 19.4 \\
Individually insured (\%) & 8.2 & 14.2 \\
- by standard contracts & 8.2 & 4.4 \\
- by GR contracts & - & 9.8 \\
Publicly insured (\%) & 9.1 & 9.1 \\
Insured by ESHI (\%) & 57.3 & 57.3 \\
\hline
\end{tabular}

Table 7: Insurance statistics before and after the introduction of GR contracts (steady-state)

This can be explained by the fact that individuals buy guaranteed renewable insurance when they are still in good health and therefore are able to renew it at a relatively low premium once their health deteriorates. Table 8 illustrates this point further by showing that people buying guaranteed renewable contracts tend to have higher expected medical expenses than those buying standard contracts.

\begin{tabular}{|l|c|c|c|c|}
\hline & Insurance & Average $E(x)$ & Average labor inc & Average total inc \\
\hline Baseline & Std ins & 0.057 & 1.107 & 1.246 \\
\hline New steady-state & Std ins & 0.038 & 1.326 & 1.433 \\
with GR ins & GR ins & 0.084 & 0.628 & 0.828 \\
\hline
\end{tabular}

Table 8: Average income and medical expenses for people choosing different types of contracts

Figure 7 shows that guaranteed renewable contracts crowd out standard contracts and reduce the fraction of uninsured individuals for all income quintiles. Interestingly, people in the two lowest income quintiles show the largest participation in the market for guaranteed renewable contracts. Table 8 shows that, on average, individuals buying guaranteed renewable contracts have lower incomes than those buying standard contracts. This seems surprising at first, given that guaranteed renewable contracts are more expensive than standard ones. To investigate this issue further, Figure 8 plots the fraction of people buying guaranteed renewable contracts in each asset and income quintile. It shows that the negative correlation between income and demand for guaranteed renewable contracts comes from the top two asset quintiles. In other words, individuals who buy guaranteed renewable contracts have accumulated enough assets to afford this type of contract but their income is low. These individuals are less likely to get access to ESHI since the probability of getting ESHI positively correlates with income. 

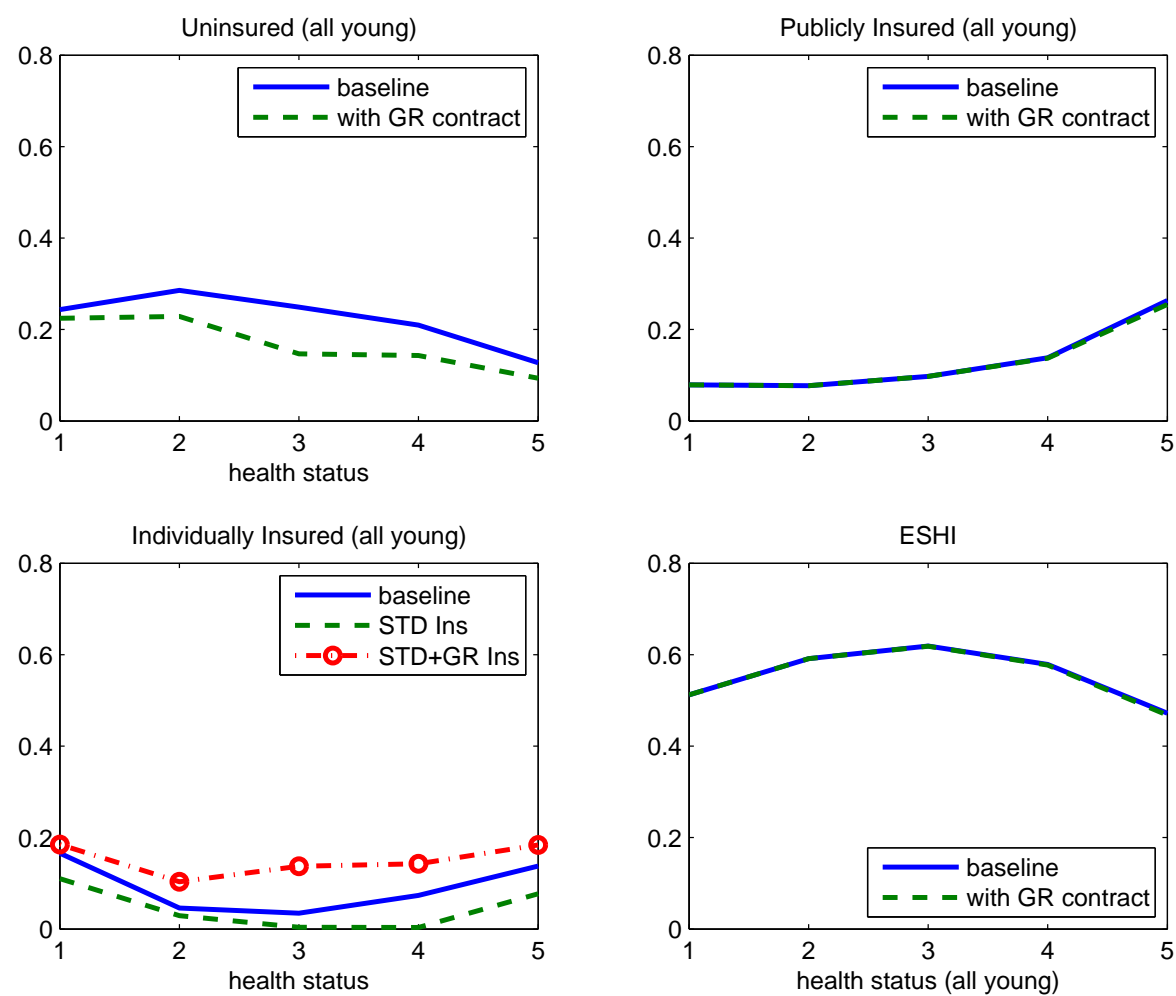

Figure 6: Insurance decisions by health status in the steady-state (+GR contract)
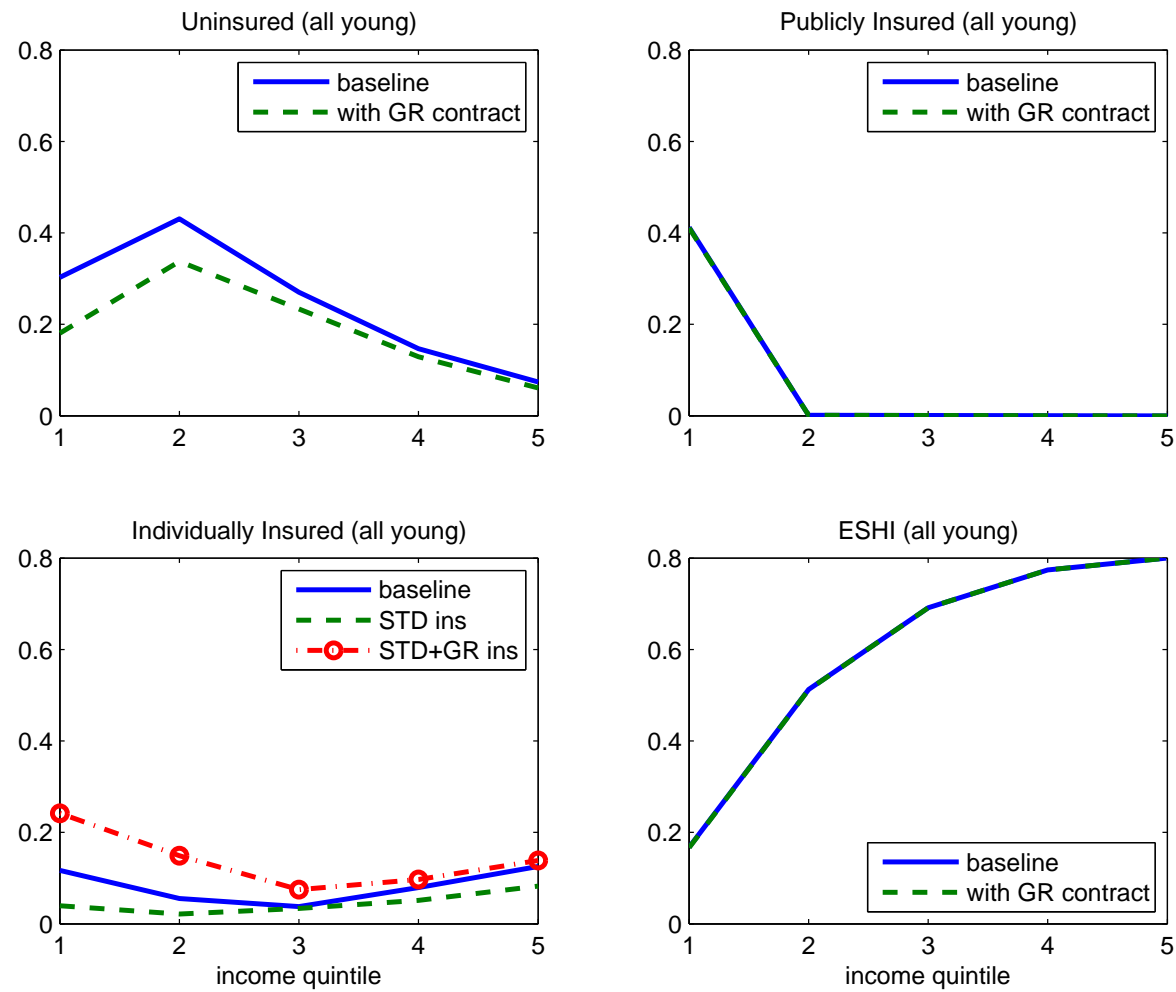

Figure 7: Insurance decisions by labor income in the steady-state (+GR contract) 
GR for asset quintile 5

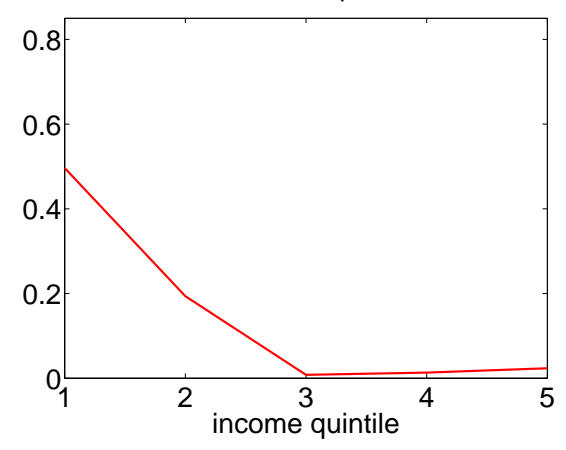

GR for asset quintile 2

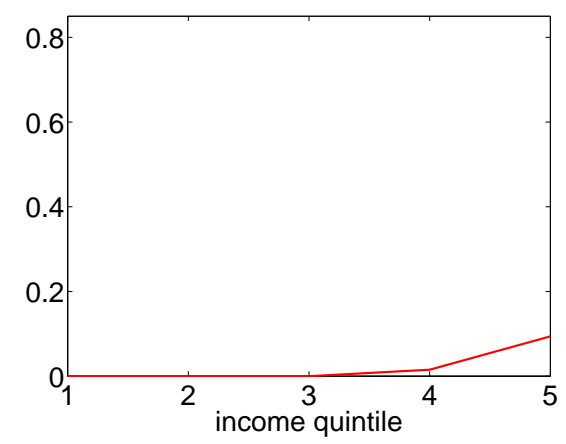

GR for asset quintile 4

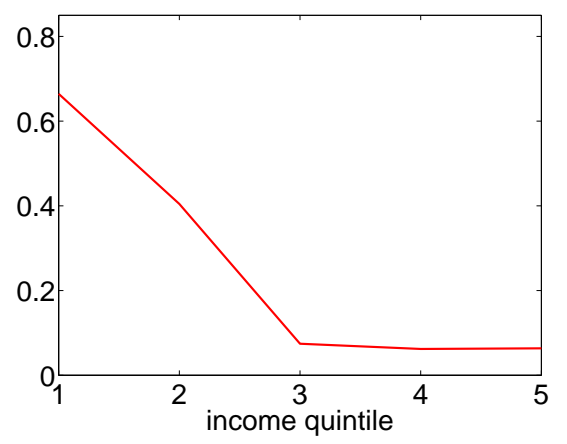

GR for asset quintile 1

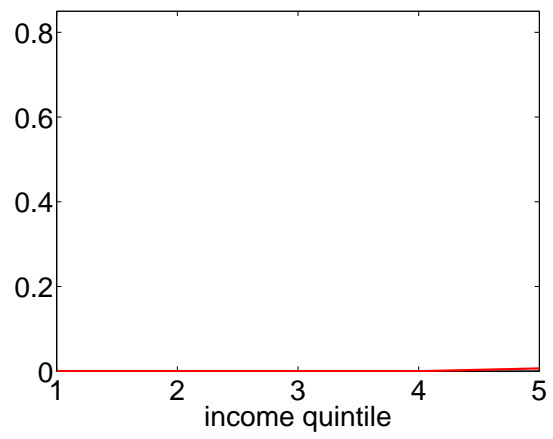

Figure 8: Fraction of people buying GR contracts by income and asset quintile

\subsection{Welfare analysis}

The first row of Table 9 illustrates the welfare gains when moving to an economy where guaranteed renewable contracts are available. Despite the fact that guaranteed renewable contracts provide good protection against reclassification risk, the resulting welfare gains are small. A newborn in the new economy needs a compensation equivalent to $0.0170 \%$ of his annual consumption if he is to live in the baseline economy. If we take transition periods into account, the average welfare gains among all young slightly increase to $0.0696 \% .^{22}$

Figure 9 shows that the consumption equivalent variation in the first period where guaranteed renewable contracts become available differs substantially by income and

\footnotetext{
${ }^{22}$ In Section 8 we show that this result is robust to the alternative design of guaranteed renewable contracts, the amount of labor income risk, and the degree of actuarial unfairness in the health insurance market.
} 


\begin{tabular}{|c|c|c|}
\hline \multirow{2}{*}{ Experiments } & \multicolumn{2}{|c|}{ average $\mathrm{CEV}$} \\
\hline & newborn & all young \\
\hline Benchmark & $0.0170 \%$ & $0.0696 \%$ \\
\hline Effect of Medicaid and ESHI & & \\
\hline - No Medicaid program & $0.0171 \%$ & $0.0715 \%$ \\
\hline - No ESHI program & $0.0537 \%$ & $0.1774 \%$ \\
\hline - No Medicaid and ESHI program & $0.0542 \%$ & $0.1812 \%$ \\
\hline Effect of consumption floor & & \\
\hline$-0.75 \underline{c}(\$ 6,605)$ & $0.0269 \%$ & $0.1862 \%$ \\
\hline$-0.50 \underline{c}(\$ 4,403)$ & $0.0571 \%$ & $0.4134 \%$ \\
\hline$-0.25 \underline{c}(\$ 2,201)$ & $0.2136 \%$ & $1.0319 \%$ \\
\hline$-0.10 \underline{c}(\$ 880)$ & $0.8575 \%$ & $2.3293 \%$ \\
\hline $\begin{array}{l}\text { Effect of Medicaid, ESHI and consumption } \\
\text { floor combined }\end{array}$ & & \\
\hline - No Medicaid and ESHI, 0.10 $\underline{c}(\$ 880)$ & $1.3713 \%$ & $4.1645 \%$ \\
\hline
\end{tabular}

Table 9: Consumption equivalent variation after introducing GR contracts ${ }^{a}$

\begin{abstract}
${ }^{a}$ The above welfare changes are computed by comparing two economies: an economy with a setup corresponding to each experiment and an economy with the same setup but with guaranteed renewable contracts. The CEV of newborns corresponds to the comparative statics between the two steady-states, while the CEV of all young takes into account the steady-state distribution in the baseline model and the transition periods.
\end{abstract}

asset quintile. People with low income but high assets are the ones who value guaranteed renewable contracts most. This is the same group that have the highest demand for guaranteed renewable insurance as shown in Figure 8.

The small welfare gains from having explicit insurance against reclassification risk imply that in the current institutional environment people are only moderately exposed to this risk. In particular, there are several institutions that can provide implicit insurance against reclassification risk: ESHI, Medicaid and government means-tested transfers. Both Medicaid and ESHI provide health insurance at a risk-independent rate. Medicaid is free, and premiums for ESHI are community rated, i.e. they are the same for all participants in the employer-based pool. Thus, an agent with a high probability of getting access to these insurance schemes is less concerned about the risk that his premium will increase when his health deteriorates. The consumption minimum floor provides support 

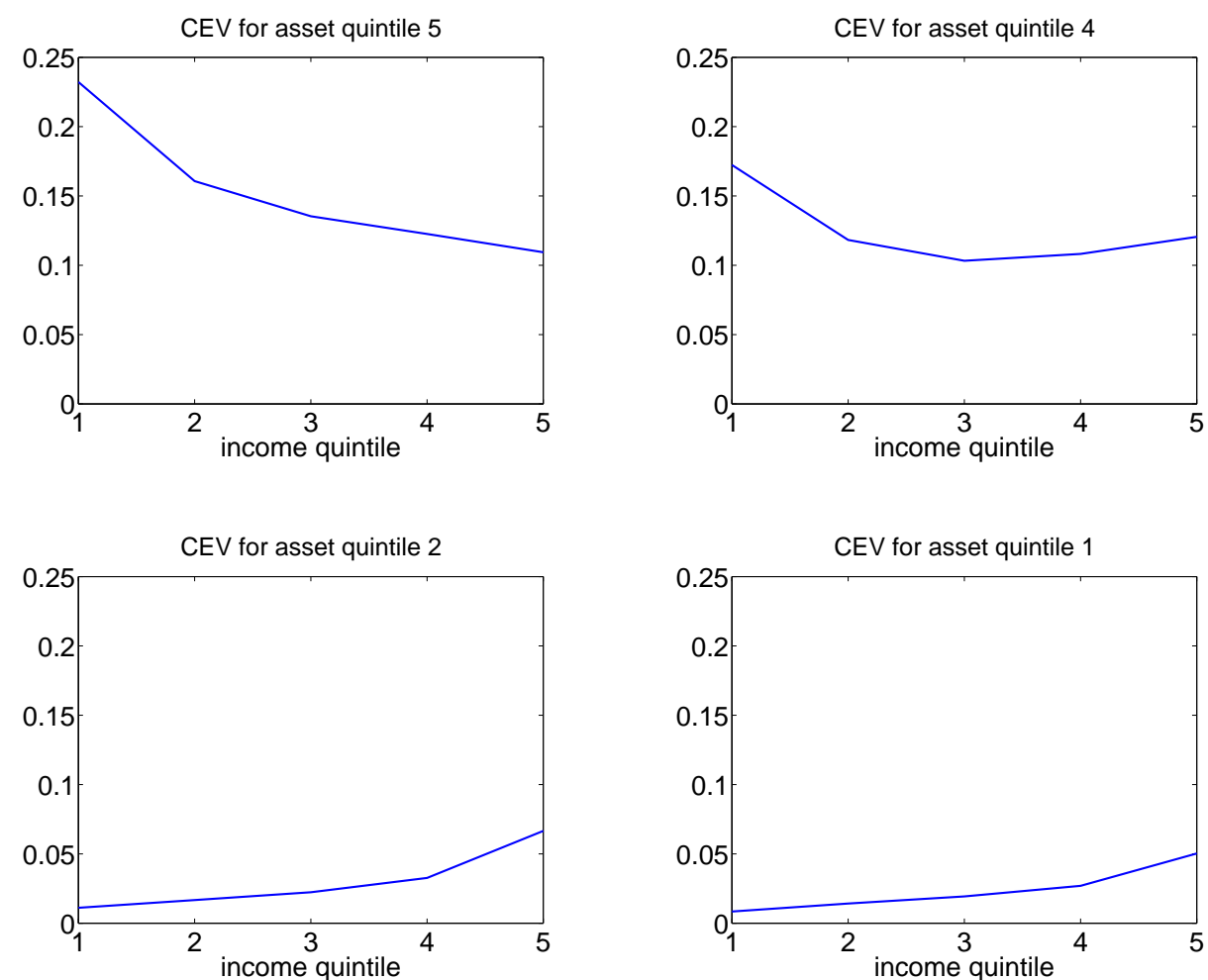

Figure 9: Consumption Equivalence by income and asset quintile (benchmark)

for people who have depleted all resources, including unhealthy individuals who cannot buy health insurance because their premiums increase. Thus, the consumption floor mitigates the consequences of the lack of protection against reclassification risk. In the next set of experiments we evaluate the importance of these institutions in providing implicit insurance against reclassification risk. ${ }^{23}$

\section{ESHI and Medicaid}

To understand the quantitative importance of ESHI and Medicaid as providers of implicit insurance against reclassification risk, we consider several counterfactual experiments. We remove ESHI, Medicaid or both of these programs from the baseline economy, and then reevaluate the welfare gains from introducing guaranteed renewable contracts. The results are presented in the third to fifth rows of Table 9. The corresponding changes in

\footnotetext{
${ }^{23}$ In all experiments, when computing welfare gains for all young, we control for the distribution of households. In general, the distribution of households can change significantly from one experiment to another. To make sure our comparisons are valid, we always compute the average welfare gains for all young using the same distribution. More specifically, in all experiments we use the steady-state distribution of the baseline economy as the initial distribution of the transition period.
} 
the individuals' insurance decisions are shown in the second and third rows of Table 10.

\begin{tabular}{|l|c|c|c|c|c|}
\hline & uninsured & Std ins & GR ins & Pub ins & ESHI \\
\hline Benchmark & 19.4 & 4.4 & 9.8 & 9.1 & 57.3 \\
No Medicaid & 28.0 & 4.6 & 10.7 & - & 57.3 \\
No ESHI & 33.1 & 7.5 & 50.1 & 9.3 & - \\
$0.75 \underline{c}(\$ 6,605)$ & 12.0 & 6.2 & 17.4 & 6.6 & 57.8 \\
$0.50 \underline{c}(\$ 4,403)$ & 7.3 & 5.9 & 24.2 & 4.2 & 58.3 \\
$0.25 \underline{c}(\$ 2,201)$ & 3.3 & 4.7 & 30.9 & 2.9 & 58.2 \\
$0.10 \underline{c}(\$ 880)$ & 2.9 & 3.7 & 33.7 & 2.4 & 57.4 \\
No Medicaid, ESHI, 0.10 $\underline{c}(\$ 880)$ & 3.0 & 1.5 & 95.0 & - & - \\
\hline
\end{tabular}

Table 10: Insurance statistics for model with GR contracts for different experiments (steady-state)

The welfare effects from introducing guaranteed renewable contracts do not change much once Medicaid is removed: the consumption equivalent variation goes up from $0.0696 \%$ to $0.0715 \%$. People who rely on Medicaid are from low-income group and likely to be eligible for government means-tested transfers, so they do not value private insurance. As observed from the second row of Table 10, most publicly insured people become uninsured once Medicaid is removed.

The situation is very different when ESHI is removed. As can be seen in the third row of Table 9, the removal of ESHI increases the consumption equivalent variation almost three times, from $0.0696 \%$ to $0.1774 \%$. This implies that without ESHI individuals are more exposed to reclassification risk, thus guaranteed renewable contracts become more valuable. ${ }^{24}$

Figures 10 and 11 illustrate this point further. The elimination of Medicaid has almost no effect on the demand for guaranteed renewable insurance for people in all income and asset quintiles. In contrast, if there is no ESHI, the take-up rates of guaranteed renewable insurance increase dramatically. The most noticeable changes are observed among highincome people in the top two asset quintiles. Previously this group had a very low demand

\footnotetext{
${ }^{24}$ Section 9 provides a more detailed comparison between ESHI and guaranteed renewable contracts as providers of guaranteed renewable insurance.
} 
for guaranteed renewable contracts, but once ESHI is removed, the majority start buying new contracts.

Figure 11 shows how welfare effects from the new contracts differ by income and asset quintile in the environment when either Medicaid or ESHI is not available. People who gain most from having explicit insurance against reclassification risk in the absence of ESHI are those in the high-income group. In the baseline economy, most of these people have access to community rated insurance through their employers. For them, ESHI is a good source of reclassification risk insurance. Once this institutional feature is removed, high-income people place much higher value on having access to guaranteed renewable contracts.
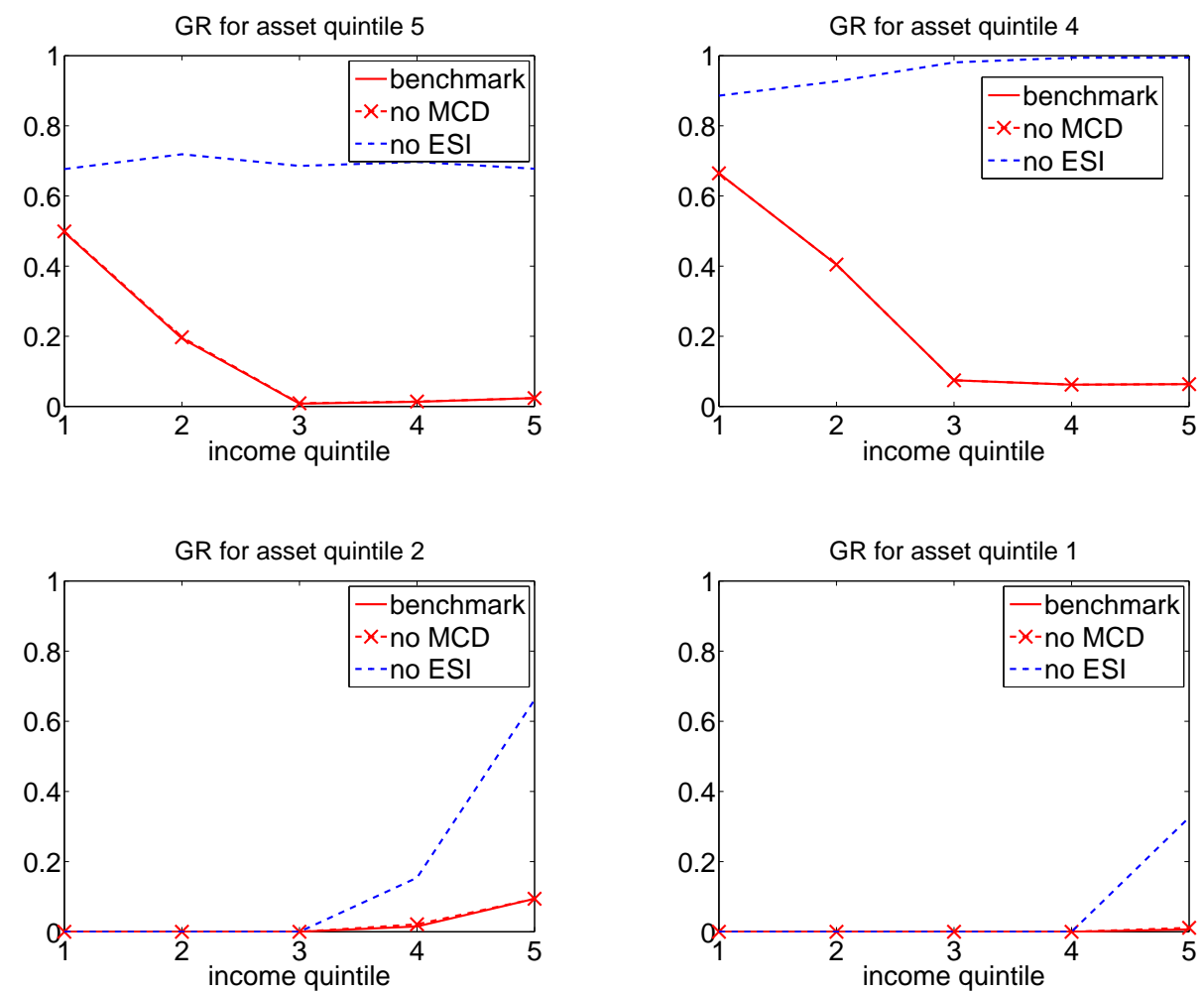

Figure 10: Fraction of people buying GR contracts by income and asset quintile (effect of ESHI/MCD) 

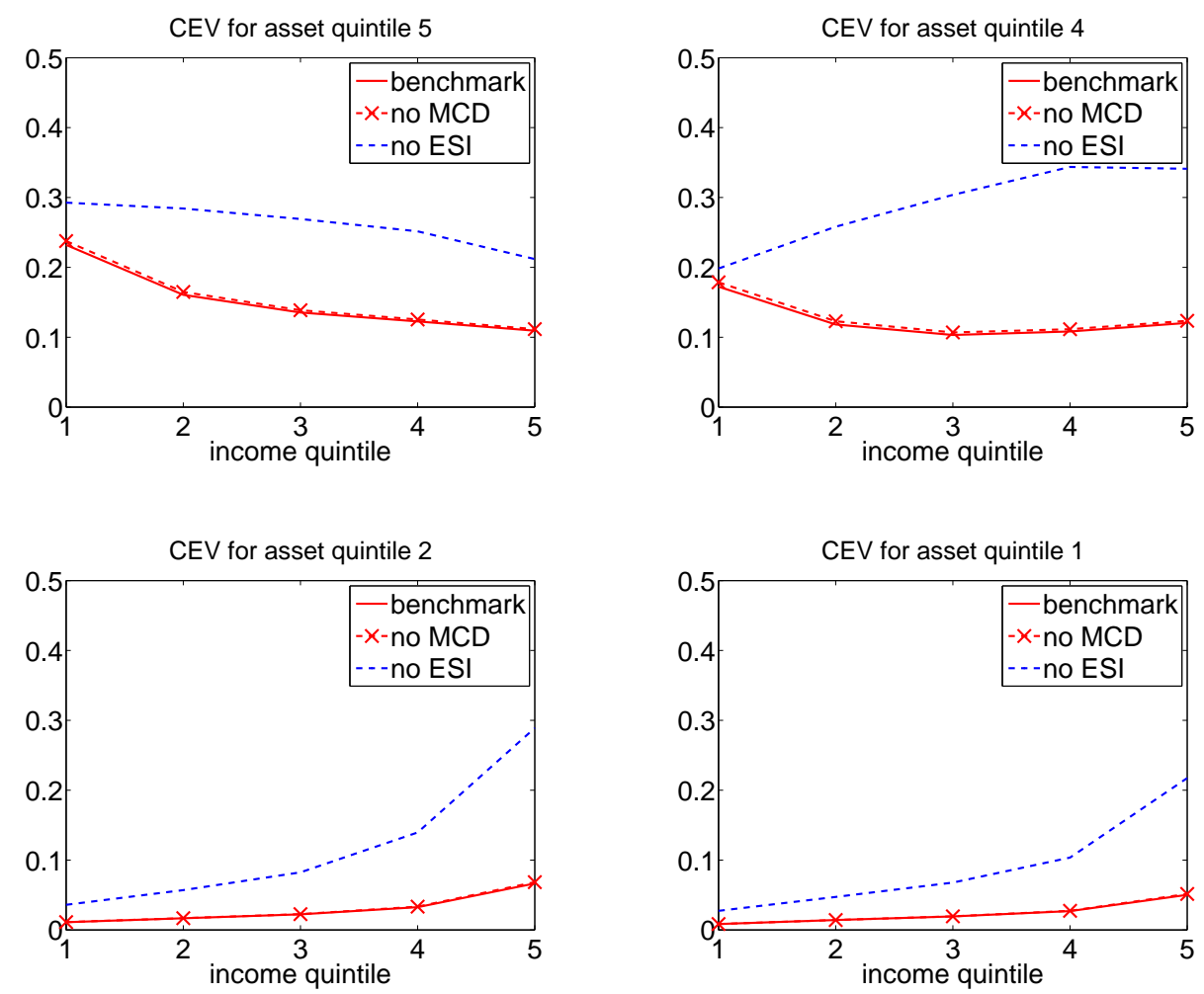

Figure 11: Consumption Equivalence by income and asset quintile (effect of ESHI/MCD)

\section{Minimum consumption floor}

To understand the role of the minimum consumption floor in providing implicit insurance against reclassification risk, we reevaluate the welfare gains from guaranteed renewable contracts in an economy with reduced government means-tested transfers. The seventh to tenth rows of Table 9 show the welfare effects when the consumption minimum floor is equal to $75 \%, 50 \%, 25 \%$ and $10 \%$ of its level in the baseline model. The resulting changes in the welfare gains are substantial. When the consumption floor decreases to $10 \%$ of the baseline level, the average consumption equivalent variation increases more than 30 times - from $0.0696 \%$ to $2.3293 \%$.

To illustrate the role of the minimum consumption floor in more detail, Figures 12 and 13 show how the demand for guaranteed renewable contracts and welfare gains change in response to a decline in the consumption floor for people with different income and asset levels. In terms of the demand for new insurance contracts, most noticeable changes are observed among people in the bottom two asset quintiles. When the consumption floor is 
reduced to $25 \%$ of the baseline level, many people in this group start buying guaranteed renewable contracts, while previously their participation in this market was almost zero (Figure 8). We do not see a similar response from the high-asset group because they buy guaranteed renewable contracts even when the consumption floor is high. Those high-asset individuals who do not buy guaranteed renewable contracts are insured by ESHI and a change in the consumption floor does not affect their insurance decisions.

In terms of welfare, the consumption equivalent variation increases substantially for all people except those in the very bottom of both income and asset distribution. The latter group has no resources and always qualifies even for the least generous means-tested transfers. It is important to note that even people with high assets value guaranteed renewable contracts substantially more once the consumption minimum floor decreases. This happens because they may also face unaffordable health insurance premiums after a sequence of bad health shocks. Since there is less chance they can rely on the consumption floor in this situation, they value explicit insurance against unaffordability of premiums more. ${ }^{25}$

\section{Environment without implicit insurance against reclassification risk}

The experiments above illustrate the quantitative importance of each of the three institutions that provide implicit insurance against reclassification risk - ESHI, Medicaid and government means-tested transfers. As a next step we consider the combined role of all these institutions in sheltering individuals from reclassification risk. More specifically, we consider an economy without ESHI, Medicaid and very low consumption guarantee $(10 \%$ of the baseline level), i.e. an economy where individuals are fully exposed to reclassification risk. The last row of Table 9 reports the welfare effects of introducing guaranteed renewable contracts into this economy, and the last row of Table 10 shows the corresponding insurance statistics.

\footnotetext{
${ }^{25}$ This result is consistent with the finding of De Nardi et al. (2010) who show that social insurance has a large effect even on people at the top end of income distribution.
} 

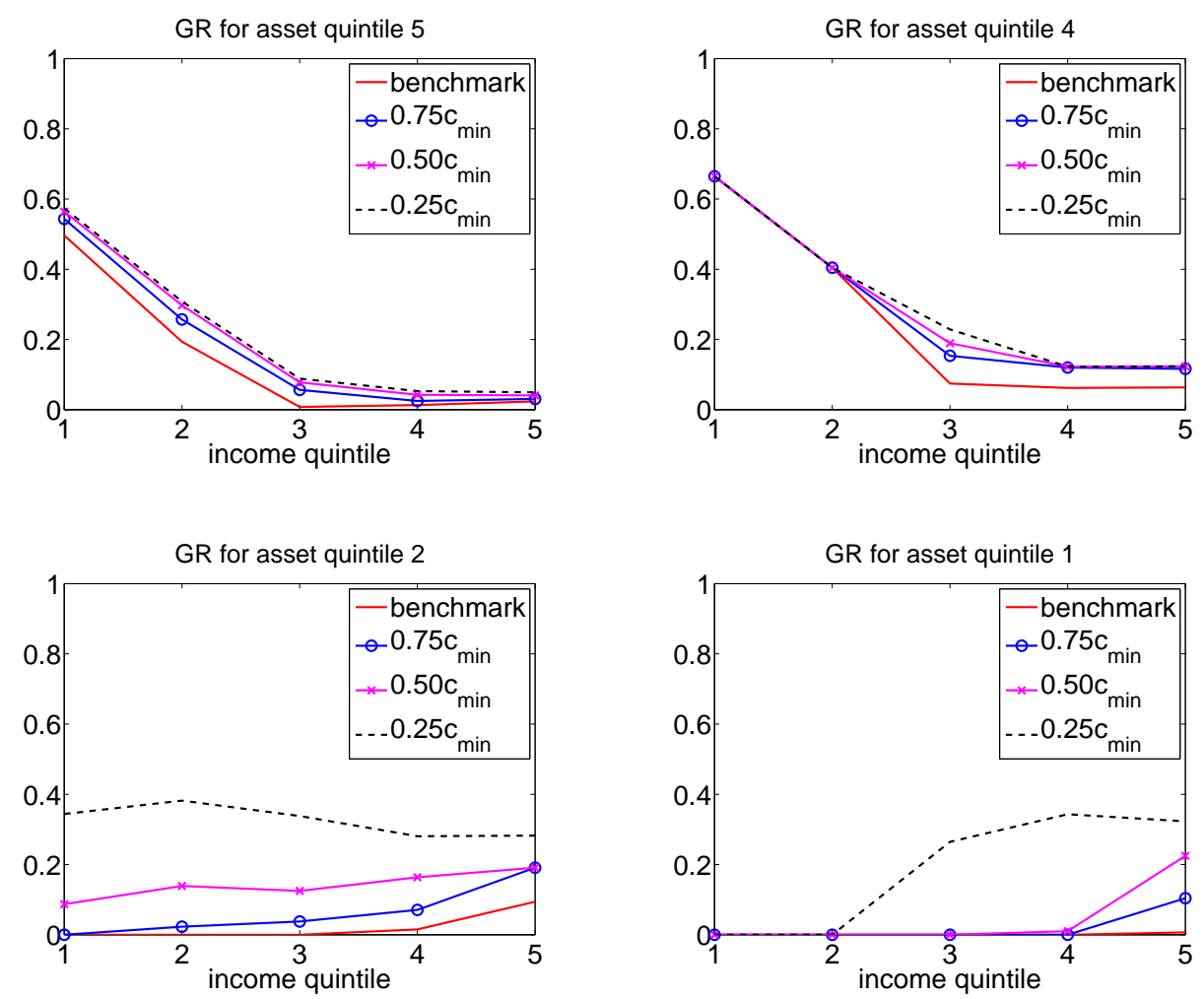

Figure 12: Fraction of people buying GR contracts by income and asset quintile (effect of $\underline{c}$ )
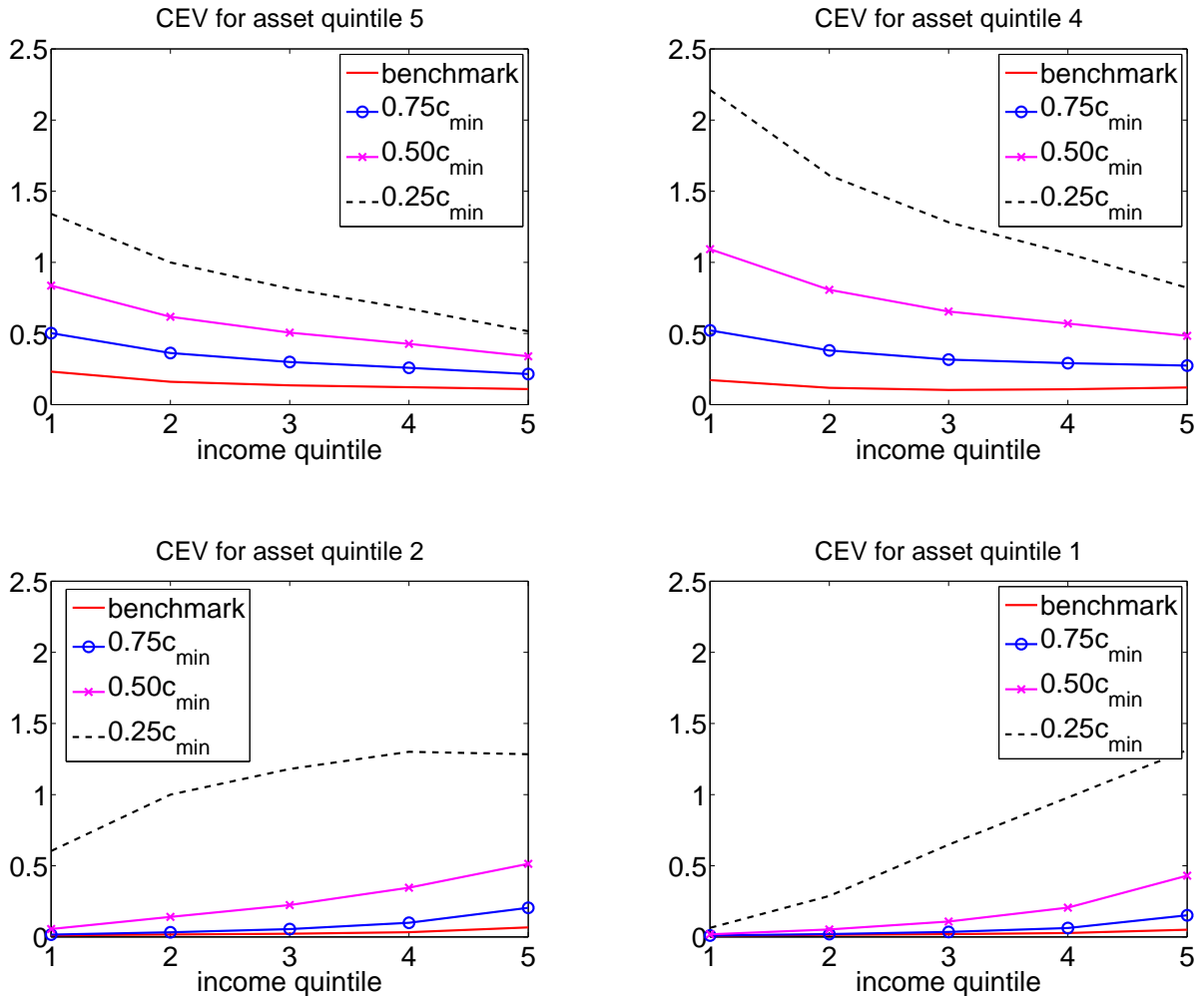

Figure 13: Consumption Equivalence by income and asset quintile (effect of $\underline{c}$ ) 
When no implicit insurance against reclassification risk is available, the value of guaranteed renewable contracts is large: the average CEV of the young is equal to $4.2 \%$. Note that the welfare gains from having access to these contracts in this economy is much higher than the sum of welfare gains in the environments where only one of the three institutions is missing. This happens because these three institutions can partially substitute for each other as providers of implicit insurance against reclassification risk. When only one of the three is removed, the other two play a more important role in sheltering individuals against this risk, thus decreasing the value of guaranteed renewable contracts. Table 10 shows that in an economy without the three institutions, 95\% of people buy guaranteed renewable contracts and only 1.5\% buy standard one-period contracts. Thus, ESHI, Medicaid and government means-tested transfers crowd-out the demand for private insurance against reclassification risk, but once these institutions are removed the absolute majority of individuals buy guaranteed renewable contracts.

\section{Implication for the health insurance reform}

In March 2010 President Obama signed the Patient Protection and Affordable Care Act that introduced significant changes in the U.S. health insurance system. This reform has two key components. First, it introduces a wide range of income-based transfers, i.e. subsidies and expansion of public coverage. Second, it changes the rules under which the individual insurance market operates. In particular, the new law does not allow insurance companies to differentiate premiums by an individual's health status thus introducing community rating in the individual insurance market. To prevent cream-skimming behavior by insurers, the reform also prohibits insurance companies from denying coverage to anyone. Finally, the new law mandates individuals to buy health insurance unless their income is very low.

Pashchenko and Porapakkarm (2013) evaluate how different components of the reform contribute to its welfare outcome and find that the contribution of community rating is very small. This paper confirms their results and provides an insight into why this 
is the case. Community rating is a regulatory approach to eliminate reclassification risk. ${ }^{26}$ In this paper we show that this risk is already, to a large extent, insured by such institutions as employer-based insurance and means-tested transfers. Thus, the introduction of community rating has a small effect on welfare.

Another implication of our findings is that good protection against reclassification risk can be obtained through private markets. Community rating accompanied by individual mandates is a large scale intervention in the insurance market. As such, it has non-trivial distorting effects on both households' and insurance firms' decisions, and thus a private market approach to solving the problem of reclassification risk may be an alternative worth considering.

\section{Discussion of the assumption of stochastic aging}

In our model, we assume that aging is stochastic, i.e. individuals are either young or old and every young person can become old with some probability. As explained in Section 4.3, our calibration strategy can to some extent mimic the life-cycle dimension in our model. In particular, newborns are more likely to be healthy and more likely to have lower productivity than the average young person (i.e. they do not draw the realization for these two variables from the invariant distribution but from the empirical distribution of people aged 20-35 in our sample). As time elapses, a newborn cohort gradually becomes more productive and less healthy. It takes around 40 periods for the distribution of a newborn cohort to converge to the invariant distribution. Thus our calibration allows the model to approximate the salient features of the life-cycle.

An important question is how the assumption of stochastic aging can affect our results. Age affects the expected medical expenses so insurance premiums should increase with age. This applies to both standard one-period and guaranteed renewable contracts. However, it is important to point out the premium for renewability (that adds up on top of the price for standard one-period insurance) actually decreases with age. This is because

\footnotetext{
${ }^{26}$ Kifman (2002) provides a detailed comparison between guaranteed renewable contracts and community rating as a means of insuring reclassification risk.
} 
all retirees are insured by Medicare, thus as an individual gets closer to retirement the maximum number of periods he will continue to renew his guaranteed renewable policy goes down.

In general, an important difference between life-cycle and stochastic-aging frameworks is that in the latter, the number of periods an individual is exposed to reclassification risk is uncertain, while in the former it is deterministic and declining with age. Thus, for people above a certain age it is cheaper to insure reclassification risk in the full lifecycle model than in the stochastic ageing one. This should increase their demand for guaranteed renewable contracts and hence the welfare effects from introducing them. On the other hand, since people in this age group are less exposed to reclassification risk they should value these contracts less and this should drive the welfare gains from introducing them downwards. It is not clear which effect will dominate. However, we expect the overall quantitative effect to be small because the two effects offset each other and also because only the welfare of older adults is affected.

\section{Robustness of welfare effects}

In this section we investigate how robust are our welfare results to the following factors:

i) different degree of front-loading of guaranteed renewable contracts, ii) labor income risk, and iii) actuarial unfairness of premiums.

\section{Different degree of front-loading}

The welfare gains from the availability of an explicit insurance against reclassification risk may be affected by the design of this insurance. Guaranteed renewable contracts are front-loaded and it is possible that the amount of front-loading is in contrast to what would be optimal from the point of view of intertemporal consumption smoothing. In general, if guaranteed renewable contracts are more front-loaded they provide more reclassification risk insurance because they lock more consumers into the contract, thus 


\begin{tabular}{|l|c|c|}
\hline \multirow{2}{*}{ Experiments } & \multicolumn{2}{c|}{ average CEV } \\
\cline { 2 - 3 } & newborn & all young \\
\hline Benchmark & $0.0170 \%$ & $0.0696 \%$ \\
Effect of front-loading & & \\
- 125\% of $p^{G R}$ & $0.0151 \%$ & $0.0645 \%$ \\
- 180\% of $p^{G R}$ & $0.0149 \%$ & $0.0622 \%$ \\
Effect of labor income risk & & \\
- reduced labor income risk & $0.0303 \%$ & $0.0244 \%$ \\
Effect of actuarial unfairness & & \\
- No administrative load $\left(\gamma^{G R}=\gamma^{I}=0\right)$ & $0.0150 \%$ & $0.0905 \%$ \\
\hline
\end{tabular}

Table 11: Consumption equivalent variation after introducing GR contracts ${ }^{a}$

${ }^{a}$ The above welfare changes are computed by comparing two economies: an economy with a setup corresponding to each experiment and an economy with the same setup but with guaranteed renewable contracts.

\begin{tabular}{|l|c|c|c|c|c|}
\hline & uninsured & Std ins & GR ins & Pub ins & ESHI \\
\hline Benchmark & 19.4 & 4.4 & 9.8 & 9.1 & 57.3 \\
$125 \%$ of $p^{G R}$ & 18.9 & 4.6 & 10.1 & 9.1 & 57.3 \\
$180 \%$ of $p^{G R}$ & 18.3 & 1.5 & 13.8 & 9.1 & 57.3 \\
Reduced labor income risk & 21.2 & 12.9 & 6.7 & 0.2 & 59.1 \\
$\gamma^{G R}=\gamma^{I}=0$ & 7.8 & 12.4 & 13.5 & 9.0 & 57.4 \\
\hline
\end{tabular}

Table 12: Insurance statistics for model with GR contracts for different experiments (steady-state)

having better risk composition as time goes by. This comes at the cost of being more expensive and also being further away from the optimal intertemporal allocation of resources. To understand whether the tradeoff between optimal consumption smoothing and reclassification risk insurance plays an important role in consumers' valuation of guaranteed renewable contracts, we consider two experiments. We reduce the degree of front-loading by increasing the price that renewable contracts guarantee, first, to $125 \%$ and then to $180 \%$ of the original price. ${ }^{27}$

Table 11 shows that lowering the degree of front-loading makes the average welfare gains smaller: the consumption equivalent variation decreases to $0.0645 \%$ and $0.0622 \%$ for

\footnotetext{
${ }^{27}$ Using example from Section 2 , this is equivalent to setting $p_{2}^{G R}=1.25 * p_{1}^{G R}$ and $p_{2}^{G R}=1.8 * p_{1}^{G R}$. In all the previous experiments we have $p_{2}^{G R}=p_{1}^{G R}$.
} 
the $125 \%$ and $180 \%$ contracts correspondingly. This suggests that the design of guaranteed renewable contracts does not affect our evaluation of welfare costs of reclassification risk.

\section{Labor income risk}

Another factor that can affect how much people value guaranteed renewable contracts is labor income risk. Uninsurable and persistent labor income shocks can affect both people's attitude towards reclassification risk and their ability to participate in longterm insurance contracts since these contracts require uninterrupted annual payments of premiums.

To understand whether labor income shocks significantly affect people's valuation of insurance against reclassification risk, we conduct an experiment where we reduce labor income risk. Specifically, in this experiment we change the labor income distribution in such a way that the cross-sectional variance of labor income is equal to $15 \%$ of the baseline case. ${ }^{28}$ As shown in Table 11, the average welfare gain from having a protection against reclassification risks is still small; more specifically the consumption equivalence drops from $0.0696 \%$ to $0.0244 \%$. Table 12 shows that less people buy guaranteed renewable contracts when facing lower labor income risks: the fraction of people with new contracts goes down from $9.8 \%$ to $6.7 \%$. This suggests that labor income risk does not prevent people from buying guaranteed renewable contracts. On the contrary it makes the additional insurance more valuable. ${ }^{29}$

\footnotetext{
${ }^{28}$ Technically, we keep the joint transition matrix of health, labor income, and ESHI offer the same as in the baseline model but assign a new labor income for each income grid. Denote $z_{j}$ and $\widehat{z}_{j}$ as the original and new value for each income grid $j$. We define $\widehat{z}_{j}=0.15 z_{j}+0.75 \bar{z}$, where $\bar{z}$ is the crosssectional average labor income in the baseline model. Since the invariant distribution over each income grid is the same, it is easy to show that the cross-sectional average of $\widehat{z}$ is $\bar{z}$, while its cross-sectional variance is $15 \%$ of that in the baseline case.

${ }^{29}$ As discussed in De Santis (2007), the welfare function is convex in the overall consumption risk. Labor income shocks augment overall risk, thus removing the labor income risk makes the welfare cost of any additional uncertainty smaller.
} 


\section{Actuarial unfairness of premiums}

Finally, we consider whether actuarial unfairness plays an important role in the valuation of guaranteed renewable contracts. Even if reclassification risk is costly in terms of welfare, people may not value insurance against this risk if it is actuarially unfair. We consider the case when administrative loads are entirely eliminated from both standard and guaranteed-renewable contracts. ${ }^{30}$ The results of this experiment are presented in the last column of Table 11. The welfare gains change very little, going up from $0.0696 \%$ to $0.0905 \%$, suggesting that actuarial unfairness does not significantly affect people's valuation of guaranteed renewable contracts.

\section{$9 \quad$ ESHI vs guaranteed renewable contracts as providers of reclassification risk insurance}

In Section 5.3 we show that ESHI crowds out the demand for guaranteed renewable insurance because it also provides protection against reclassification risk. Table 9 shows that in the absence of ESHI the demand for guaranteed renewable contracts and welfare gains from introducing them are high. Our purpose in this section is to provide a more detailed comparison between community-rated employer-based insurance and guaranteed renewable insurance. Both provide protection against reclassification risk but in a different way: ESHI redistributes from the sick to the healthy in the same time period, while guaranteed renewable contracts allow healthy individuals to move resources to the state when they are unhealthy in the future.

\begin{tabular}{|l|c|c|c|c|c|c|}
\hline & CEV & uninsured & Std ins & GR ins & Pub ins & ESHI \\
\hline Baseline & - & 25.4 & 8.20 & - & 9.1 & 57.3 \\
No ESI+GR & $-0.1675 \%$ & 33.1 & 7.5 & 50.1 & 9.3 & - \\
No ESI+GR (tax ded.+emp. contr) & $-0.1143 \%$ & 18.6 & 5.9 & 66.5 & 9.0 & - \\
\hline
\end{tabular}

Table 13: CEV and insurance statistics when ESHI is substituted with GR contracts

\footnotetext{
${ }^{30}$ In other words, we set $\gamma^{I}=\gamma^{G}=1$.
} 
To better understand the difference and the similarity between these two insurance mechanisms we run two additional experiments. We start by comparing the baseline economy (with ESHI) with the economy that has no ESHI but only guaranteed renewable contracts. The first row of Table 13 shows the resulting ex-ante welfare effects as well as the distribution of people by insurance status. Substituting ESHI with guaranteed renewable contracts produces the welfare loss equivalent to $0.1675 \%$ of the annual consumption. Part of the reason is that ESHI is not a pure insurance mechanism but it has several other institutional features attached to it. First, ESHI premiums are tax deductible, i.e. every individual buying health insurance through his employer gets a tax subsidy. Second, employers contribute most of the premium (83\% in our calibration).

To account for this, in the next experiment we allow individuals to buy guaranteed renewable contracts either directly through the individual market or through their employer (if they get an offer). In the latter case we assume that the employer contributes $83 \%$ of the guaranteed renewable contracts' premiums and that these premiums are tax deductibles. We assume that the probability to get an offer to buy health insurance through the employer is the same as in the baseline economy. The second row of Table 13 shows that in this case newborns still prefer to live in the baseline economy with ESHI rather than in the economy with guaranteed renewable contracts but welfare loss are less $(0.1143 \%$ of the annual consumption). Note that these negative welfare effects do not mean that guaranteed renewable contracts provide worse insurance than ESHI. The fifth column of Table 13 shows that in the latter experiment $66.5 \%$ of the young buy guaranteed renewable contracts, while only $57.3 \%$ of the young buy ESHI in the baseline economy. However, the community-rated ESHI has implicit income redistribution embedded in it. This happens because community rating makes the healthy pay for the sick. Since healthy people tend to have higher incomes these transfers are progressive. Guaranteed renewable contracts remove these transfers and this produces negative welfare effects. In other words, guaranteed renewable contracts result in smaller welfare since these contracts only provide pure insurance. However, it is always possible to augment guaranteed renewable contracts with income-based transfers to achieve any 
desirable welfare gains.

\section{Conclusion}

This paper studies how important reclassification risk is for the welfare of consumers. Reclassification risk is believed to be an important problem in the individual health insurance market because premiums in this market are risk-rated while a typical contract lasts for only one year. Individuals whose health status deteriorates can see a drastic increase in their health insurance premiums, and this reduces their ability to obtain health insurance.

We constructed a general equilibrium model and calibrated it using the MEPS dataset to replicate the key features of the U.S. economy. To evaluate the welfare costs of reclassification risk, we consider the effect of introducing into this economy guaranteed renewable health insurance contracts. Guaranteed renewable contracts are private insurance contracts that provide protection against reclassification risk without requiring consumers' commitment or income-based transfers.

We find that in the current institutional environment individuals are well-sheltered against reclassification risk and the welfare gains from having access to the explicit insurance against it are small. We show that two institutions - employer-based insurance and consumption minimum floor - provide good implicit protection against reclassification risk. Without these institutions, i.e. when individuals are fully exposed to reclassification risk, welfare gains from having access to guaranteed renewable contracts exceed $4 \%$ of the annual consumption.

\section{Acknowledgements}

We thank all seminar participants at the University of Virginia, Federal Reserve Bank of Richmond, QSPS Summer Workshop, PET Meeting in Bloomington, SED Meeting in Ghent, GRIPS, Asian Meeting of the Econometric Society in Seoul, Uppsala University, 
and especially, Huberto Ennis, John Jones, Ping Wang, Eric Young, and the anonymous referee for their comments and suggestions. The authors acknowledge financial support from the Research and Development Administration Office at the University of Macau. All errors are our own. 


\section{References}

[1] Cochrane, J., 1995. Time-consistent Health Insurance. The Journal of Political Economy, 103(3), 445-473

[2] De Nardi, M., French, E., Jones, J., 2010. Why Do the Elderly Save? Journal of Political Economy, 118(1), 39-75

[3] De Santis, M., 2007. Individual Consumption Risk and the Welfare Cost of Business Cycles. American Economic Review, 97(4), 1488-1506

[4] Diamond, P., 1992. Organizing the Health Insurance Market. Econometrica, 60(6), $1233-5124$

[5] Finkelstein, A., McGarry, K., Sufi, A., 2005. Dynamic Inefficiencies in Insurance Markets: Evidence from Long-term Care Insurance. American Economic Review Papers and Proceedings, 95(2), 224-228

[6] French, E., Jones, J., 2004. On the distribution and dynamics of health care costs. Journal of Applied Econometrics 19, 705-721.

[7] French, E., Jones, J., 2011. The Effects of Health Insurance and Self-Insurance on Retirement Behavior. Econometrica, 79(3), 693-732

[8] Gouveia, M., Strauss, R, 1994. Effective Federal Individual Income Tax Functions: An Exploratory Empirical Analysis. National Tax Journal, 47, 317-339

[9] Hansen, G., Hsu, M., Lee, J., 2014. Health Insurance Reform: The impact of a Medicare Buy-In. Journal of Economic Dynamics and Control, 45, 315-329.

[10] Hendel, I., Lizzeri, A., 2003. The Role of Commitment in Dynamic Contracts: Evidence from Life Insurance. The Quarterly Journal of Economics, 118(1), 299-327

[11] Hsu, Minchung, 2013. Health Insurance and Precautionary Saving - A Structural Analysis. Review of Economic Dynamics, 16:3, 511-526

[12] Kennickell, A., 2003. A Rolling Tide: Changes In the Distribution of Wealth in the U.S., 1989-2001. Working paper, Federal Reserve Board

[13] Kahn, J., Kronick, R., Kreger, M., Gans, D. 2005. The Cost of Health Insurance Administration in California: Estimates for Insurers, Physicians, and Hospitals, Health Affairs 24

[14] Kiffman, M., 2002. Insuring Premium Risk in Competitive Health Insurance Market. Ed. Mohr Siebek

[15] Kitao, S., Jeske, K., 2009. U.S. Tax Policy and Health Insurance Demand: Can a Regressive Policy Improve Welfare? Journal of Monetary Economics, 56(2), 210-221

[16] Pashchenko, S., Porapakkarm, P., 2013. Quantitative Analysis of Health Insurance Reform: Separating Regulation from Redistribution. Review of Economic Dynamics, 16(3), 383-404 
[17] Pauly, M., Kunreuther, H., Hirth, R., 1995. Guaranteed Renewability in Insurance. Journal of Risk and Uncertainty, 10, 143-156

[18] Sommers, J., 2002. Estimation of Expenditures and Enrollments for EmployerSponsored Health Insurance. Agency for Healthcare Research and Quality, MEPS Methodology Report 14

[19] Young, E., 2010. Solving the Incomplete Markets Model with Aggregate Uncertainty Using the Krusell-Smith Algorithm and Non-Stochastic Simulations. Journal of Economic Dynamics and Control, 34(1), 36-41. 


\title{
Welfare costs of reclassification risk in the health
}

\author{
insurance market:
}

Appendix

(Supplementary materials)

\author{
Svetlana Pashchenko* \\ University of Surrey
}

\author{
Ponpoje Porapakkarm ${ }^{\dagger}$ \\ National Graduate Institute \\ for Policy Studies (GRIPS)
}

April 7, 2015

\section{A Competitive equilibrium with asymmetric infor- mation $^{1}$}

Given the government programs $\left\{\underline{c}, s s, q^{\text {med }}(x), p^{\text {med }}\right\}$, the insurance coverage $\{q(i, x)\}$, the fraction of the group premium contributed by the employer $(\psi)$, the competitive equilibrium with asymmetric information consists of the set of equilibrium prices $\left\{w, r, p, p^{I}(h), p^{G R}(i)\right\}$, wage reduction $\left\{c_{E}\right\}$, households' value functions $\left\{\mathbf{V}^{y}(\boldsymbol{s}), \mathbf{V}^{o}(\mathbf{s})\right\}$, decision rules for the young $\left\{c(\boldsymbol{s}), k^{\prime}(\boldsymbol{s}), i^{H}(\boldsymbol{s})\right\}$ and for the old $\left\{c(\boldsymbol{s}), k^{\prime}(\boldsymbol{s})\right\}$, the tax function $\{\mathcal{T}(y)\}$,

\footnotetext{
${ }^{*}$ Corresponding author. Address: School of Economics, Faculty of Business, Economics and Law, University of Surrey, Guildford, GU2 7XH, UK, Tel. +44 148368 2773. Email: svetlanap.econ@gmail.com

${ }^{\dagger}$ Email: p-porapakkarm@grips.ac.jp

${ }^{1}$ We refer to this equilibrium as asymmetric information equilibrium because insurance companies observe only one state variable - health status. For guaranteed renewable contracts health is not the only variable relevant for pricing which creates an asymmetric information environment.
} 
time-invariant distributions $\left\{\Gamma^{y}(\mathbf{s}), \Gamma^{o}(\mathbf{s})\right\}$, and the set of insurers' beliefs $\left\{\pi_{t+j}\left(h_{t+j} \mid h_{t}\right) ; j>0, \forall t\right\}$ such that the following conditions are satisfied:

1. Given the set of prices and the tax function, decision rules and value functions solve individuals' optimization problems (2) and (7).

2. Wage $(w)$ and rent $(r)$ satisfy Equations (15) and (16).

3. Labor market clears: $L=\int z \Gamma^{y}(\boldsymbol{s})$

4. Capital market clears. Since guaranteed renewable contracts are front-loaded, there will be a balance carrying over time for each contract. We need to take this balance into account when computing the aggregate capital. Denote by $\theta_{t+j}^{t}\left(h_{t}\right)$ an ex-post balance at time $t+j$ of a unit of contract sold at time $t$ to an individual with health status $h_{t}$. One period after the contract is originated this balance takes the following form:

$$
\begin{aligned}
\theta_{t+1}^{t}\left(h_{t}\right)= & p^{G R}\left(h_{t}\right)(1+r)-\gamma^{I} E M\left(h_{t}\right)+ \\
& p^{G R}\left(h_{t}\right) \int_{h_{t+1}} \frac{\mathcal{F}\left(h_{t+1}, i_{t+1}^{H}=R G R \| h_{t}, i_{t}^{H}=B G R\right)}{\Gamma^{y}\left(h_{t}, i_{t}^{H}=B G R\right)} .
\end{aligned}
$$

The first term on the right-hand side is the premium collected at the initiation of the contract and carried on to the next period. The second term is the cost of medical claims in period $t+1$. The last term is the revenue from the contract renewal. We can define recursively the ex-post balance $j$ periods after the contract is originated as follows ${ }^{2}$ :

$$
\begin{gathered}
\theta_{t+j}^{t}\left(h_{t}\right)=\theta_{t+j-1}^{t}\left(h_{t}\right)(1+r)- \\
\gamma^{I} \int_{h_{t+j-1}} E M\left(h_{t+j-1}\right) \frac{\mathcal{F}\left(h_{t+j-1}, i_{t+j-1}^{H}=R G R \| h_{t}, i_{t}^{H}=B G R\right)}{\Gamma^{y}\left(h_{t}, i_{t}^{H}=B G R\right)}+ \\
p^{G R}\left(h_{t}\right) \int_{h_{t+j}} \frac{F\left(h_{t+j}, i_{t+j}^{H}=R G R \| h_{t}, i_{t}^{H}=B G R\right)}{\Gamma^{y}\left(h_{t}, i_{t}^{H}=B G R\right)} .
\end{gathered}
$$

\footnotetext{
${ }^{2}$ By recursively substituting $\theta_{t+j-1}^{t}$, this equation is equivalent to Equation (19).
} 
Thus the capital market clearing condition in period $t$ can be written as:

$$
\begin{gathered}
K=\int k^{\prime}(\mathbf{s}) \Gamma^{y}(\mathbf{s})+\int k^{\prime}(\mathbf{s}) \Gamma^{o}(\mathbf{s})+ \\
p \int \mathbf{1}_{\left\{i^{H}(\mathbf{s})=B G\right\}} \Gamma^{y}(\mathbf{s})+\int \mathbf{1}_{\left\{i^{H}(\mathbf{s})=B I\right\}} p^{I}(h) \Gamma^{y}(\mathbf{s})+ \\
\int \mathbf{1}_{\left\{i^{H}(\mathbf{s})=B G R\right\}} p^{G R}(h) \Gamma^{y}(\mathbf{s})+\sum_{j=1}^{\infty} \int \theta_{t}^{t-j}\left(h_{t-j}\right) \Gamma^{y}\left(h_{t-j}, i_{t}^{H}(\mathbf{s})=B G R\right)
\end{gathered}
$$

5. $c_{E}$ satisfies Equation (17); thus the firm offering ESHI earns zero profit.

6. The tax function $\{\mathcal{T}(y)\}$ satisfies the government budget balance in Equation (22).

7. Standard one-period insurance premiums, $p^{I}(h)$, satisfy Equation (18), guaranteed renewable premiums $p^{G R}(i), i=1, \ldots, H$, satisfy Equation (19), and the group insurance premium $(p)$ satisfies Equation (21). Thus health insurance companies earn zero expected profit on each contract.

8. Insurance companies' beliefs $\left\{\pi_{t+j}\left(h_{t+j, t} \mid h_{t}\right) ; j>0, \forall t\right\}$ satisfy Equation (20) if $\Gamma^{y}\left(h_{t}, i_{t}^{H}=B G R\right) \neq 0$. Otherwise,

$$
\pi_{t+j}\left(h_{t+j} \mid h_{t}\right)=0 \quad ; \quad j>0, \forall t .
$$

The last equation is the off-equilibrium belief of insurers. When no one with health status $h_{t}$ buys a guaranteed renewable contract, insurers believe that if someone with health $h_{t}$ buys a guaranteed renewable contract, he will not renew the contract in the next period ${ }^{3}$.

\section{B Transition matrices for health status}

The health status transition matrix for young households, $G^{y}\left(h^{\prime} \mid h\right)$, is

\footnotetext{
${ }^{3}$ Our results are robust to an alternative specification of the off-equilibrium beliefs.
} 


\begin{tabular}{|l|l|l|l|l|}
\hline 0.619 & 0.264 & 0.092 & 0.022 & 0.002 \\
\hline 0.261 & 0.432 & 0.260 & 0.044 & 0.003 \\
\hline 0.094 & 0.257 & 0.517 & 0.122 & 0.010 \\
\hline 0.070 & 0.142 & 0.414 & 0.341 & 0.034 \\
\hline 0.013 & 0.096 & 0.274 & 0.372 & 0.245 \\
\hline
\end{tabular}

and the transition matrix for retired households, $G^{o}\left(h^{\prime} \mid h\right)$, is

\begin{tabular}{|l|l|l|l|l|}
\hline 0.626 & 0.225 & 0.111 & 0.037 & 0.001 \\
\hline 0.257 & 0.416 & 0.265 & 0.058 & 0.005 \\
\hline 0.131 & 0.324 & 0.427 & 0.108 & 0.011 \\
\hline 0.090 & 0.170 & 0.455 & 0.242 & 0.043 \\
\hline 0.056 & 0.174 & 0.388 & 0.336 & 0.046 \\
\hline
\end{tabular}

Here the first row corresponds to $h=1$ and the first column corresponds to $h^{\prime}=1$.

\section{Computational algorithm}

We solved for the steady state equilibrium of the baseline model as follows.

1. Guess the initial interest rate $r$, the price in the group insurance market $p$, the amount the firm offering ESHI subtracts from the wage of their workers $c_{E}$, prices of guaranteed renewable contracts $p^{G R}(h), h=1 . . H$, and the tax parameter $a_{2}{ }^{4}$.

2. Guess the value functions for the young and the old. Solve the problems for the young and the old. We optimize with respect to savings and insurance decisions and evaluate the value function for points outside the state space grid using a Piecewise Cubic Hermite Interpolating Polynomial (PCHIP). Update the value functions and continue iterating until both value functions converge. Use convergent value functions to find the policy functions.

3. Given the policy functions, simulate the households distribution using a nonstochastic method as in Young (2010).

\footnotetext{
${ }^{4}$ We cannot prove the uniqueness of the equilibrium in the health insurance market, however our results are robust to alternative initial guesses of insurance prices $\left(p\right.$ and $\left.p^{G R}(h), h=1 . . H\right)$.
} 
4. Use the distribution of households and policy functions to compute the government budget deficit/surplus. Gradually update the tax function parameter $a_{2}$, the interest rate $r$, insurance prices $p^{G R}(h), h=1 . . H, p$, and the substraction from wage $c_{E}$. Repeat steps 2-3 until all these variables converge.

\section{Guaranteed renewable insurance with frictions}

Our results show that if individuals gain access to a frictionless market offering guaranteed renewable contracts this results in small average welfare gains. ${ }^{5}$ An alternative approach to understand the value of guaranteed renewable insurance is to introduce these contracts in the baseline economy and quantify the size of frictions needed to deter people from buying them (the outcome observed in reality). In this section we take this second approach and introduce frictions in the market for guaranteed renewable contracts as an extra cost embedded in the premium. One can think of the extra cost arising from two sources. First, to offer guaranteed renewable contracts, insurance companies need to commit to the long-term contract and thus require a compensation for future uncertainties, which are potentially large. The growth rate of the aggregate medical expenses is difficult to predict, particularly in the far future. ${ }^{6}$ In addition, the invention of new treatments, and changes in clinical guidelines or standards can significantly alter the dynamics of reclassification risks, specifically the transition probability of medical expenses in our model, which is the basis for pricing guarantee renewable contracts. Second, guaranteed renewable contracts are more complicated than regular insurance contracts, and consumers may need to put more efforts to understand them.

To illustrate how large the extra cost that eliminates the demand for guaranteed re-

\footnotetext{
${ }^{5}$ The premium for guaranteed renewable contract consists of two parts. First is the premium for the regular one-period health insurance. We assume this premium is the same as in the market offering standard one period contracts meaning it includes an administrative load. Second is the premium for the right to renew the contract at the prespecified price. This part of the premium has no administrative costs or any other loads. We refer to the guaranteed renewable market introduced in the benchmark experiments of our paper as frictionless to stress the fact that the option to renew the contract is priced actuarially fair.

${ }^{6}$ Cutler(1996) argues that the lack of long-term health insurance can be explained by the uncertainty in the aggregate medical costs.
} 


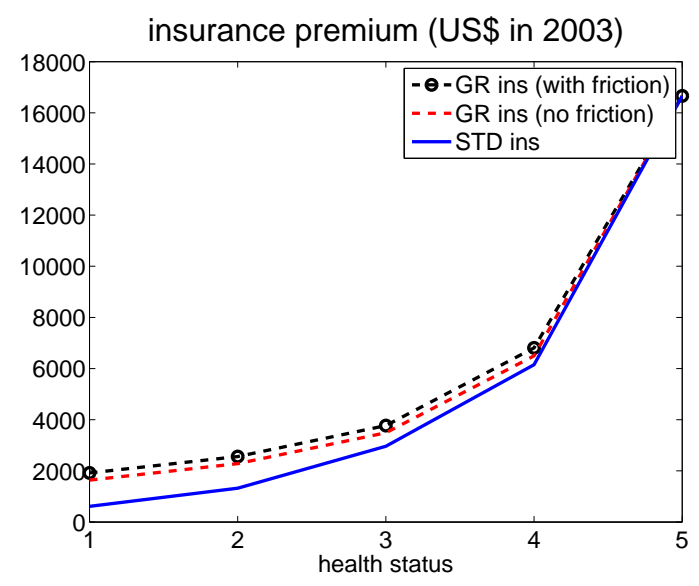

Figure A1: The difference in premiums between frictionless guaranteed renewable contracts and guaranteed renewable contracts with an extra cost

newable contracts should be, we use the following approach. We start with the benchmark economy with frictionless guaranteed renewable contracts (as described in Section 6) and gradually increase its premiums, $p^{G R}(h)$, till the take-up rate of each GR contract is less than $0.25 \%{ }^{7}$ Figure (A1) compares the premiums of guaranteed renewable contracts in this experiment with the steady-state premiums reported in Section 6. The differences between the two premiums are $\$ 283, \$ 276, \$ 280$, and $\$ 310$ for the contract initiated by a person in medical grids $1,2,3$, and 4 respectively. In terms of the percentage difference, the premiums in the market with frictions are higher than frictionless premiums by $17 \%, 12 \%, 8 \%$, and $5 \%$ for people in medical grids $1,2,3$, and 4 respectively. Thus, relatively small fixed costs can eliminate the demand for guaranteed renewable contracts, which is consistent with our result that these contracts bring small welfare gains when employers' sponsored health insurance and the minimum consumption guarantee coexist. It is worth noting that the additional costs needed to wipe out the demand for guarantee renewable contracts need not to be large partly because of the adverse selection effect. A small increase in premiums for guaranteed renewable contracts will repel people with low probability to renew the contract in later periods. This increases the costs for insurers

\footnotetext{
${ }^{7}$ Instead of completely eliminating the demand for guaranteed renewable contracts, we change the premiums until the size of the market becomes very small. We do this to avoid the result when our assumption about off-equilibrium beliefs influences the equilibrium. One can argue that firms would stop offering insurance contracts if there is too few participants in the market.
} 
to provide the option to renew the contract. Consequently, the premium increases which decreases the demand of guaranteed renewable contracts even further. 